\title{
The Dendritic Lamellar Body: A New Neuronal Organelle Putatively Associated with Dendrodendritic Gap Junctions
}

\author{
C. I. De Zeeuw, ${ }^{1,2,3}$ E. L. Hertzberg, ${ }^{3}$ and E. Mugnaini' \\ 'Laboratory of Neuromorphology, Biobehavioural Sciences, University of Connecticut, Storrs, Connecticut 06269- \\ 4154, '2Department of Anatomy, Erasmus University Rotterdam, 3000 DR, Rotterdam, The Netherlands, and \\ ${ }^{3}$ Department of Neuroscience, Albert Einstein College of Medicine (D.C.S.), New York, New York 10461
}

\begin{abstract}
It is shown in rat that antiserum $\alpha 12 B / 18$ specifically labels a new lameliar organelle that is exclusively located in dendritic appendages. These dendritic lamellar bodies occur in a restricted number of brain regions, which include areas like the inferior olive, area CA1 and CA3 of the hippocampus, dentate gyrus, olfactory bulb, and cerebral cortex. In these regions the neurons with lamellar bodies form dendrodendritic gap junctions. Immunoreactivity in the inferior olive is first detected between P9 and P15, which coincides with the development of gap junctions in this nucleus. In the adult inferior olive, the density of dendritic lamellar bodies is highest in the rostral medial accessory olive, the subnucleus where electrotonic coupling is most prominent.
\end{abstract}

Antiserum $\alpha 12 B / 18$, thus, specifically detects a new neuronal organelle that may be related to dendrodendritic gap junctions.

[Key words: inferior olive, hippocampus, cerebral cortex, dentate gyrus, olfactory bulb, hypothalamus, electrotonic coupling]

Gap junctions are the morphological correlate of electrotonic coupling (Robertson, 1963; Sotelo and Korn, 1978; Sotelo and Triller, 1981; for reviews see Peters et al., 1970; Bennett and Goodenough, 1978; Loewenstein, 1981). These electrotonic synapses occur between neurons as well as between glial cells (Massa and Mugnaini, 1982; Mugnaini, 1986). Areas in the brain where neuronal gap junctions have been found at relatively high densities by standard electron microscopy (EM) are the inferior olive (IO), (Sotelo et al., 1974; Rutherford and Gwyn, 1977; Angaut and Sotelo, 1989; De Zeeuw et al., 1989) and the hippocampus (Schmalbruch and Jahnsen, 1981; Kosaka and Hama, 1985; Matsumoto et al., 1991). These findings have been confirmed by electrophysiological recordings and/or dye coupling (Llinás, 1974; Llinás et al., 1974; MacVicar and Dudek, 1980, 1981, 1982; Llinás and Yarom, 1981; Andrew et al., 1982; MacVicar et al., 1982; Benardo and Foster, 1986; Llinás and

\footnotetext{
Received Apr. 27, 1994; revised June 29, 1994; accepted July 27, 1994.

We thank Richard Corpiana, Eddie Dalm, Erika Goedknegt, Mary Goss, Richard Hawkings, and Hans Van Der Burg for their excellent technical assistance. Studies by E.L.H. and E.M. were supported by grants from the NIH; C.I.D.Z. and E.L.H. are recipients of the KNAW award and the Career Scientist award from the Irma T. Ilirschl Trust, respectively.

Correspondence should be addressed to C. I. De Zeeuw, Department of Anatomy, Erasmus University Rotterdam, P.O Box 1738. 3000 DR, Rotterdam, The Netherlands.
}

Copyright 1995 Society for Neuroscience $0270-6474 / 95 / 151587-18 \$ 05.00 / 0$
Sasaki, 1989; Sasaki et al., 1989). To date, there has been no description of any neuronal structure, other than the gap junction, that appears to be associated with electrotonically coupled neurons.

More recently, antibodies and mRNA probes have been used to detect the distribution of gap junctions, but these latter markers are unable to indicate, directly or indirectly, specifically the presence of neuronal gap junctions (Nagy et al., 1988; Dermietzel, 1989; Shiosaka et al., 1989: Yamamoto et al., 1989a. 1990a,c; Naus et al., 1990; Matsumoto et al., 1991; Micevych and Abelson, 1991).

In the present study we tested a new polyclonal antiserum $(\alpha 12 B / 18)$. This antiserum was raised to a bovine serum albumin (BSA)-conjugated peptide corresponding to amino acid sequence 49-61 of the first putative extracellular loop of heart muscle gap junction protein connexin43 (Cx43; Beyer et al., 1987; Fishman et al., 1990; Kumar and Gilula, 1992). The Western blots made in this study indicated that $\alpha 12 \mathrm{~B} / 18$ includes not only antibodies against $\mathrm{Cx} 43$, but also against other, possibly related, proteins. It is shown that antiserum $\alpha 12 \mathrm{~B} / 18$ provides punctate labeling in a restricted number of brain areas, among which the $\mathrm{IO}$ and the hippocampus stand out. These puncta do not correspond to glial or neuronal gap junctions, but to a new neuronal organelle.

To investigate to what extent this organelle and neuronal gap junctions can be associated with one another, all brain areas with substantial immunoreactivity were examined for the presence of gap junctions in the EM. In addition, we compared (1) the occurrence of the organelle with the occurrence of gap junctions during development of the IO (see Bourrat and Sotelo, 1983) and (2) the differences in densities of the organelle among the olivary subnuclei with the differences in levels of electrotonic coupling between these nuclei (see Llinás and Yarom, 1981).

\section{Materials and Methods \\ Antiserum $\alpha 12 \mathrm{~B} / 18$ was tested on its specificity with the use of com- petition tests, affinity purification, and Western immunoblots. The dis- tribution of the immunoreactive puncta in adult and young rats revealed with the use of antiserum $\alpha 12 \mathrm{~B} / 18$ was analyzed quantitatively at the light microscopic level. CNS regions with a high or intermediate density of immunoreactive puncta were processed for immuno- and standard EM to identify the cellular structures labeled by the antiserum. In ad- dition, standard electron microscopic sections of the rabbit and cat IO were examined.}

\section{Light microscopy}

Specificity tests. To test the specificity of antiserum $\alpha 12 \mathrm{~B} / 18$, brain sections of the IO of the rat were processed for immunocytochemistry with (1) preimmune serum; (2) antiserum $\alpha 12 \mathrm{~B} / 18$ preabsorbed with the syn- 

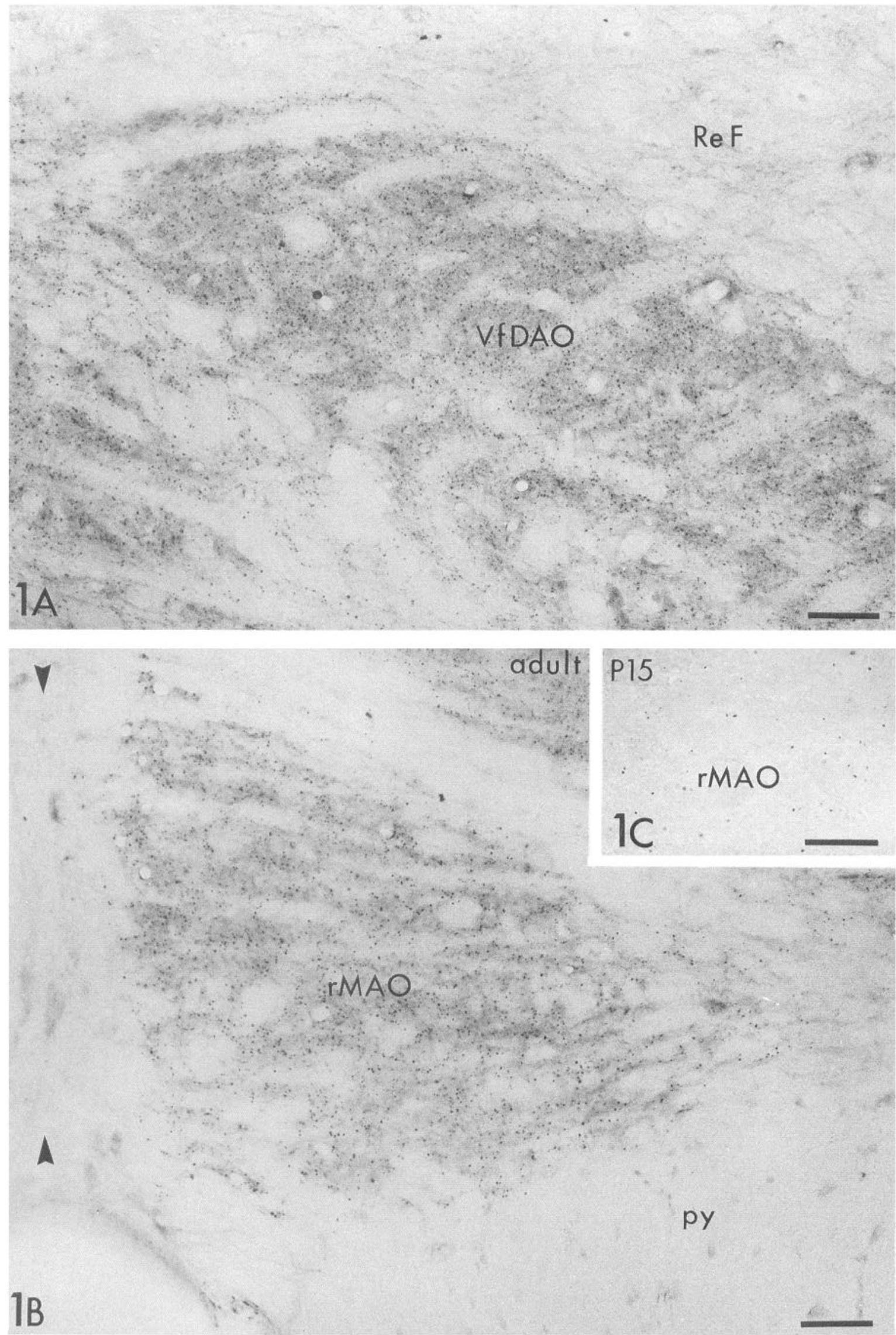

Figure 1. Punctate labeling in the IO of an adult rat $(A, B)$ and a young, P15 rat $(C)$ with the use of antiserum $\alpha 12 \mathrm{~B} / 18$. Note the total absence of immunoreactivity in the reticular formation $(R e F)$ dorsal to the $\mathrm{VfDAO}(A)$ as well as in the pyramidal tract $(p y)$ ventral to the rMAO $(B)$. Arrowheads indicate midline. Sections were cut in the transversal plane. Scale bars: $A, 45 \mu \mathrm{m} ; B, 41 \mu \mathrm{m} ; C, 36 \mu \mathrm{m}$. 

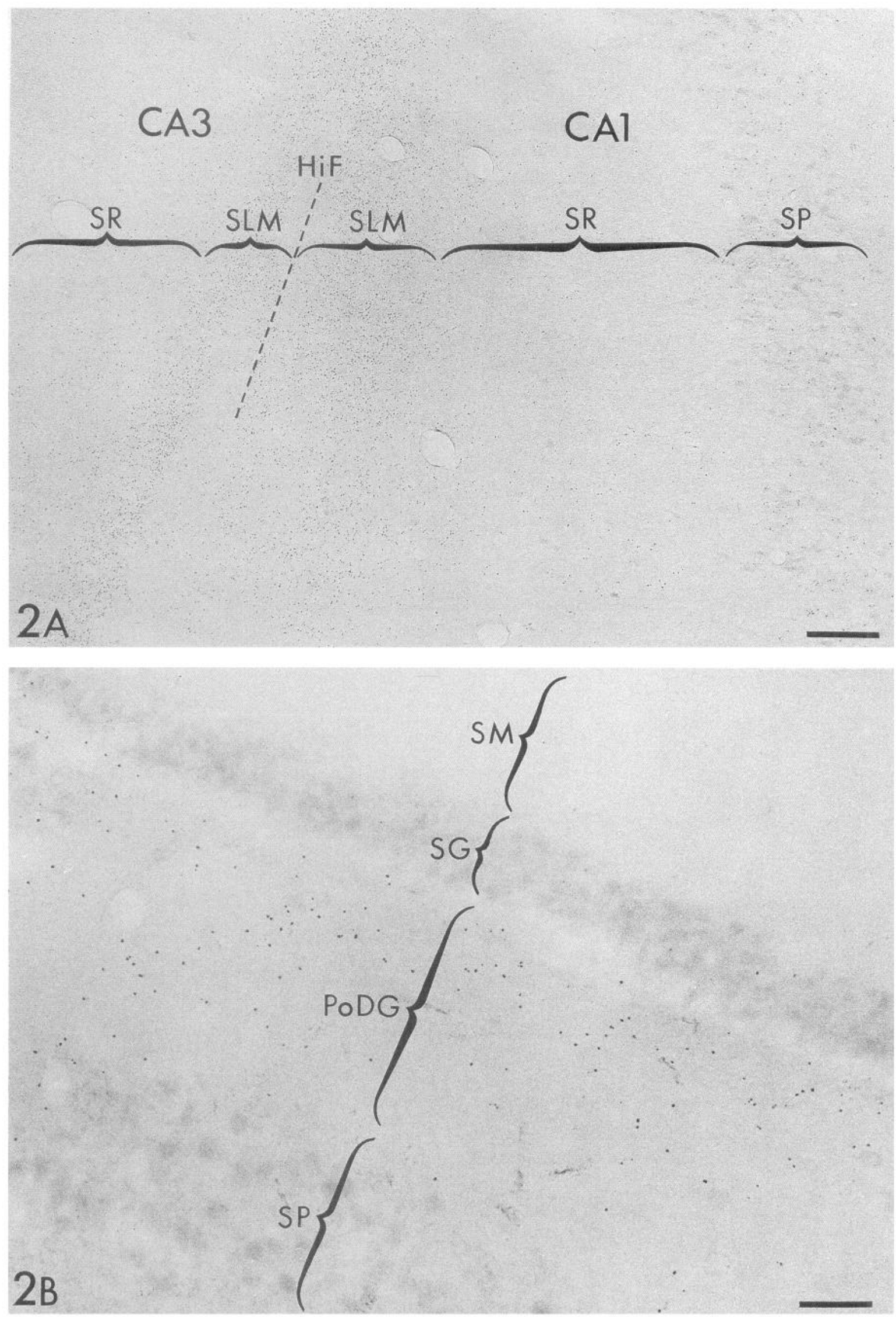

Figure 2. Punctate labeling in the hippocampal $(A)$ and dentate gyri $(B)$ of an adult rat with the use of antiserum $\alpha 12 B / 18$. In $A$, a high density of immunoreactive puncta is present in the stratum lacunosum moleculare (SLM) of both area CA1 and CA3 along the ventral HiF (dashed line), while the stratum radiatum $(S R)$ and stratum pyramidale $(S P)$ contain a low density of puncta. In $B$, the PoDG contains an intermediate density of puncta that are relatively large compared to other areas in the brain. Note the absence of labeling in the SP, stratum granulosum $(S G)$, and stratum moleculare $(S M)$ in the dentate gyrus. Sections were cut in the transversal plane. Scale bars: $A, 121 \mu \mathrm{m} ; B, 36 \mu \mathrm{m}$. 

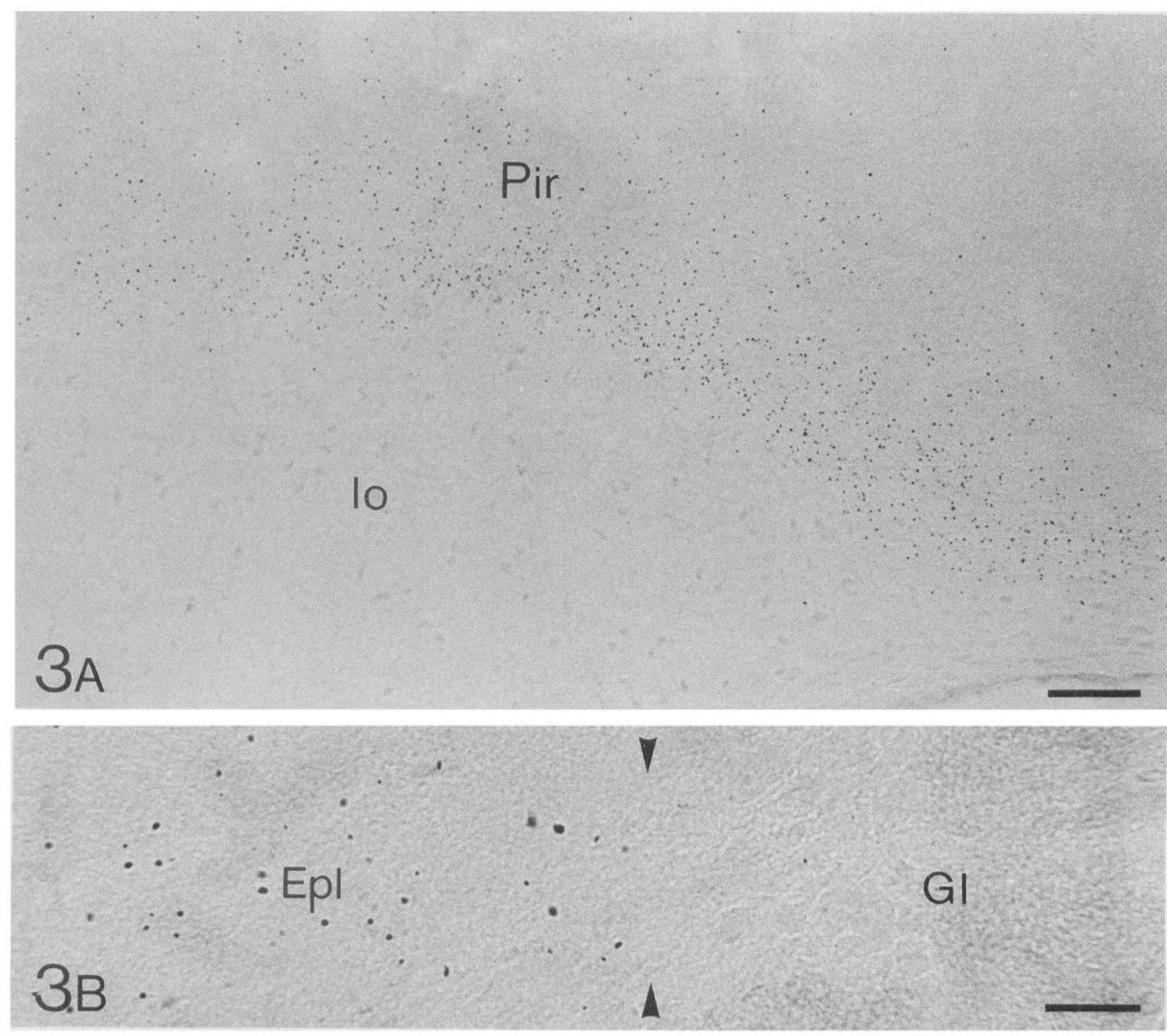

Figure 3. Punctate labeling in the Pirlo $(A)$ and Epl of the $\mathrm{OB}(B)$ of an adult rat obtained with the use of antiserum $\alpha 12 \mathrm{~B} / 18$. Note in $A$ that the immunoreactive puncta are mainly present in the first layer of the piriform cortex (Pir) directly starting at the outer part of the lateral olfactory tract $(l o)$. In the OB most of the immunoreactive puncta occur in the Epl along the glomerular layer $(G l)$. Arrowheads in $B$ indicate border between Epl and Gl. $A$ is taken from a section cut in the transversal plane, $B$ from a section cut in the horizontal plane. Scale bars: $A, 53 \mu \mathrm{m} ; B, 16 \mu \mathrm{m}$.

thetic peptide against which it was generated; (3) an affinity-purified fraction of $\alpha 12 \mathrm{~B} / 18$ made with peptide $\alpha 12 \mathrm{~B}$ linked to a matrix; and (4) the unbound fraction of antiserum $\alpha 12 \mathrm{~B} / 18$ obtained during the affinity purification. As described below in the Results it was the latter fraction that retained all activity for recognition of the dendritic lamellar bodies.

To find out whether $\mathrm{Cx} 43$ was detected by the antibody, the following tests were performed: (1) Western immunoblots were carried out on homogenates of the rat brain regions with a high density of immunoreactive puncta (for technical details see Nagy et al., 1988, 1989); (2) the immunoreactivity provided by three other antisera against $\mathrm{Cx} 43$ (designated as $\alpha 15, \alpha 16$, and $\alpha 18$ ) were compared with the present immunoreactivity; and (3) sections of the rat heart muscle were processed for immunocytochemistry. Peptides $\alpha 15, \alpha 16$, and $\alpha 18$ correspond respectively to amino acids $188-197,241-260$, and 346-360 of the rat Cx43 sequence (Beyer et al., 1987). Peptide $\alpha 15$ corresponds to a sequence located extracellularly between the third and fourth transmembrane segments of $\mathrm{Cx} 43$ while peptides $\alpha 16$ and $\alpha 18$ are located in the cytoplasmically disposed carboxy-terminus of the protein.
Immunohistochemistry. Adult and young (P9-P15) Sprague-Dawley albino rats were anesthetized with sodium pentobarbital $(45 \mathrm{mg} / \mathrm{kg})$ and perfused transcardially with $200 \mathrm{ml}$ saline followed by 0.5 (young) or 1 (adult) liter of $0.5 \%$ zinc salicylate, $4 \%$ freshly depolymerized form-

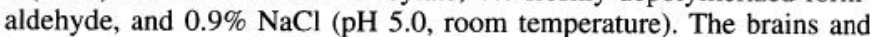
hearts were removed $1 \mathrm{hr}$ after perfusion and cryoprotected in saline containing $30 \%$ sucrose. In the adult rats, brain sections were cut from the caudal part of the spinal cord up to the olfactory bulb, while in the young animals only the IO was sectioned. Tissue was cut coronally at $20 \mu \mathrm{m}$ on a freezing microtome. In two cases half of the brain was cut horizontally or sagittally. All sections were collected in $0.25 \%$ Triton $\mathrm{X}$ in $0.5 \mathrm{M}$ Tris buffer at pH 7.6 (TT), blocked in 5\% normal donkey serum in TT, directly incubated in the primary antiserum $\alpha 12 \mathrm{~B} / 18$ diluted 1:2000 in $2 \%$ normal donkey serum in TT (DTT) for $48 \mathrm{hr}$ on a shaker at $4^{\circ} \mathrm{C}$, thoroughly rinsed in DTT, incubated for $1 \mathrm{hr}$ in goat antirabbit IgG (Sternberger-Meyer) diluted 1:50 in DTT, thoroughly rinsed in DTT, incubated in rabbit PAP (Sternberger-Meyer) diluted 1:100 in DTT for $1 \mathrm{hr}$, and rinsed as above. Finally, the sections were incubated 


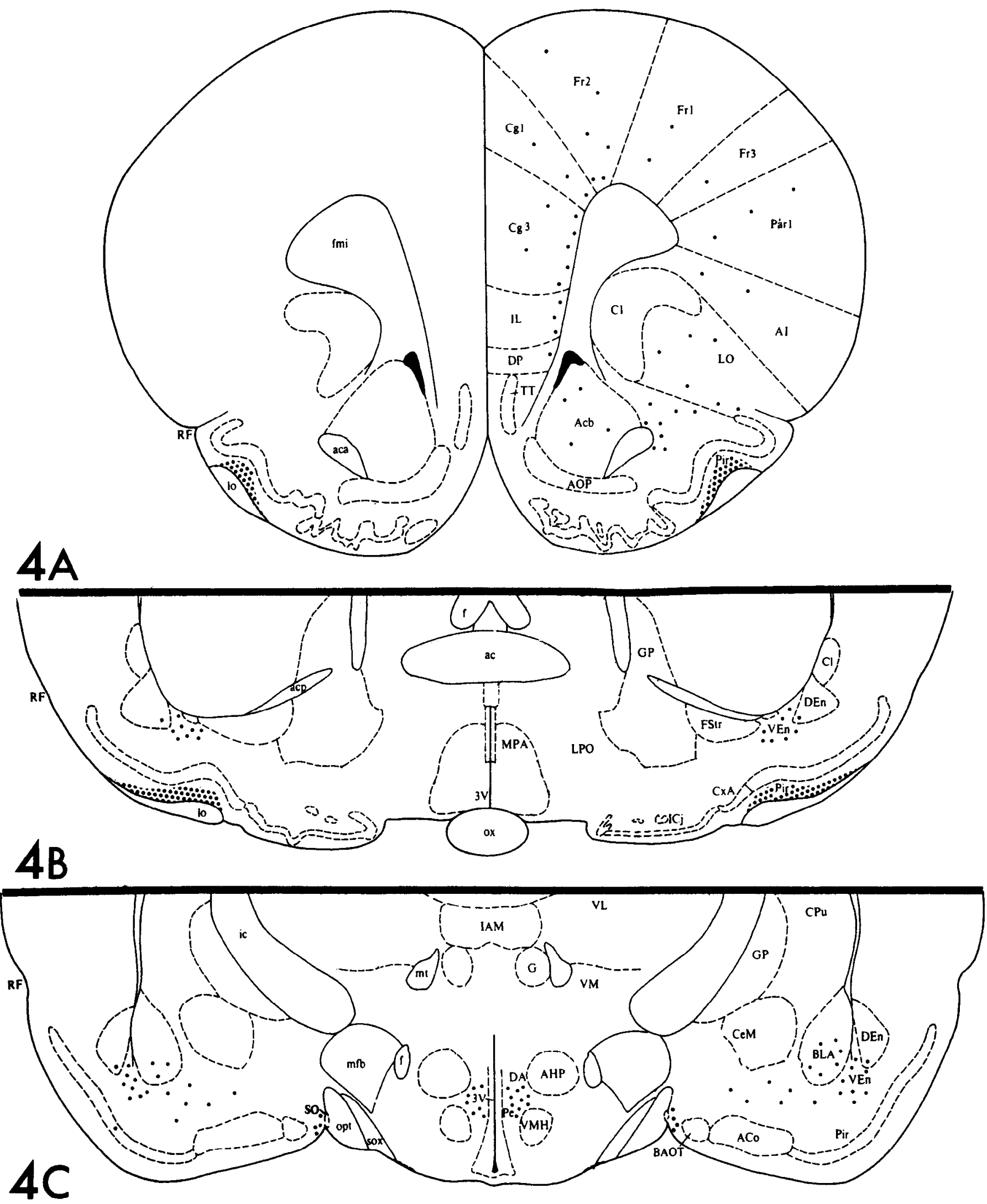

Figure 4. Schematic drawings of the distribution of immunoreactive puncta in coronal sections of the rat brain $(A-C$, from rostral to caudal). The black dots represent labeling in the different cortical areas, the ventral and dorsal endopiriform nucleus (VEn, $D E n)$, the basolateral amygdaloid nucleus $(B L A)$ and adjacent amygdala, the periventricular hypothalamic nucleus $(P e)$, and the area directly lateral of the supraoptic nucleus $(S O)$. Note that the immunoreactivity in the cingulate, frontal, and infralimbic cortical areas $(C g 1,3 ; \mathrm{Fr} l, 2,3 ; \mathrm{IL})$ is most prominent in the deeper layers of the cortex. The high density of labeling in the Pir is present along the entire lo. Abbreviations are given in Table 2 . Drawings are modified from the atlas of the rat brain by Paxinos and Watson (1986). Distance left to right equals $11.5 \mathrm{~mm}$ in $A, 14 \mathrm{~mm}$ in $B$, and $14.6 \mathrm{~mm}$ in $C$. Rostrocaudal level in $A, 2.7 \mathrm{~mm}$ anterior to bregma; $B, 0.4 \mathrm{~mm}$ posterior to bregma; $C, 2.12 \mathrm{~mm}$ posterior to bregma. 

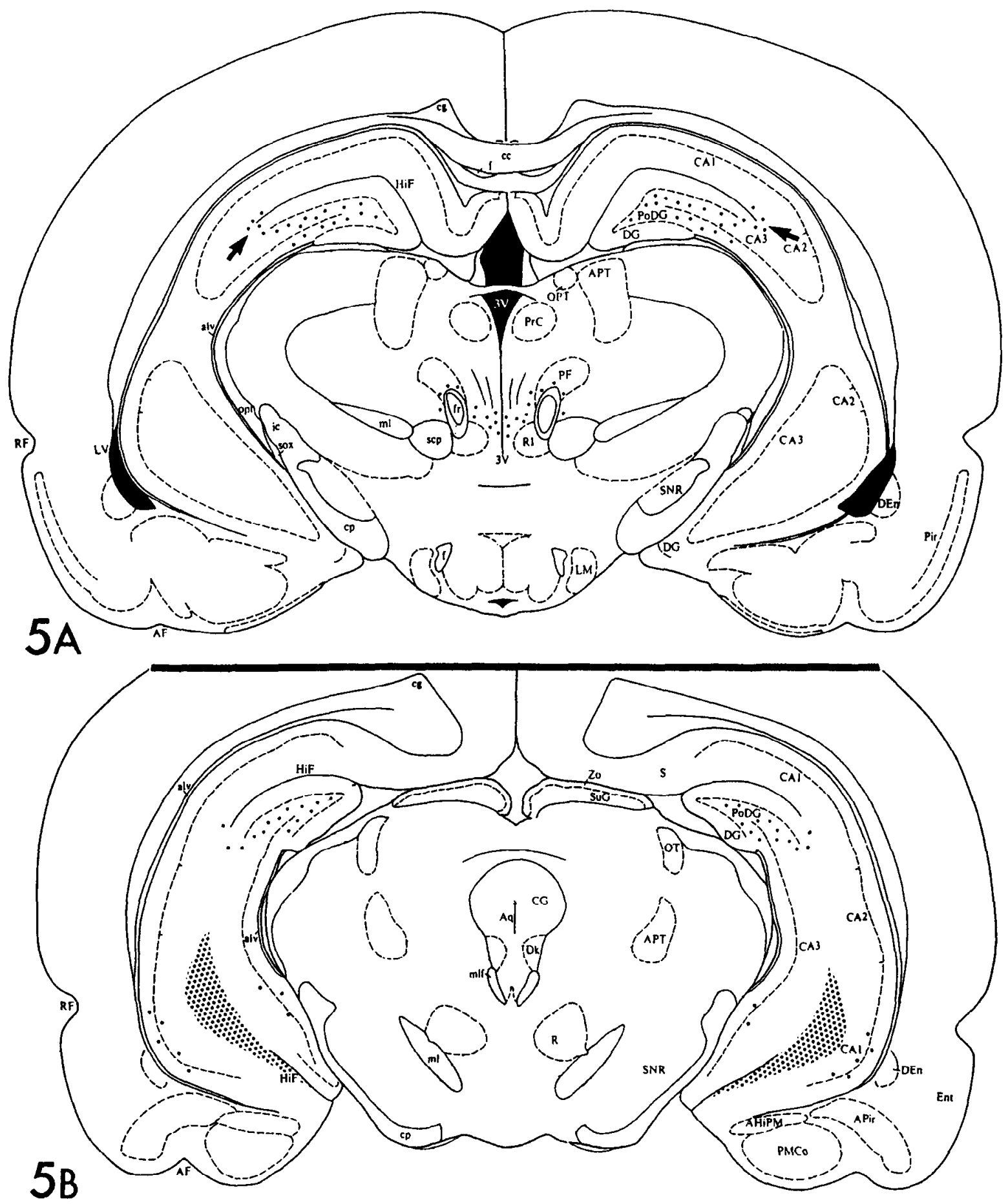

Figure 5. Schematic drawings of the distribution of immunoreactive puncta in the different hippocampal areas (PoDG, HiF, CA1, CA3). A, The sparse labeling in the SLM next to the dorsal HiF is continuous with the labeling in the stratum moleculare of the dentate gyrus (arrows). Note also the labeling in the nucleus subparafascicularis $(P F)$ of the thalamus. $B$, The labeling in the SLM is much more prominent along the ventral $\mathrm{HiF}$ than along the dorsal HiF. Abbreviations are given in Table 2. Distance left to right equals $15.6 \mathrm{~mm}$ in $A$ and $15.4 \mathrm{~mm}$ in $B$. Rostrociaudal level in $A, 4.52 \mathrm{~mm} ; B, 5.60 \mathrm{~mm}$ posterior to bregma.

for $15-20 \mathrm{~min}$ in $0.05 \%$ 3,3-diaminobenzidine (DAB) and $0.01 \% \mathrm{H}_{2} \mathrm{O}_{2}$ in $0.05 \mathrm{M}$ Tris buffer, mounted, and coverslipped.

The brain and heart sections processed for control with the preimmune serum, purified antibodies, and antisera $\alpha 15, \alpha 16$, and $\alpha 18$ were processed in the same way except that the concentration of the primary was adjusted when necessary.

Collection and analysis of the data. The sections of four adult and two young rat brains processed with antiserum $\alpha 12 B / 18$ were quanti- tatively analyzed with the use of a light microscope equipped with a surface area frame. For each brain area with immunoreactivity we determined the absolute number of puncta per surface area in that plane of focus (with the condenser at a fixed level) that provided the maximum number of puncta. In case of the IO this quantification was done for every subnucleus (for definitions of olivary subdivisions in rat, see Nelson and Mugnaini, 1988); the data for these different subnuclei were obtained from the same sections. The densities obtained from several 


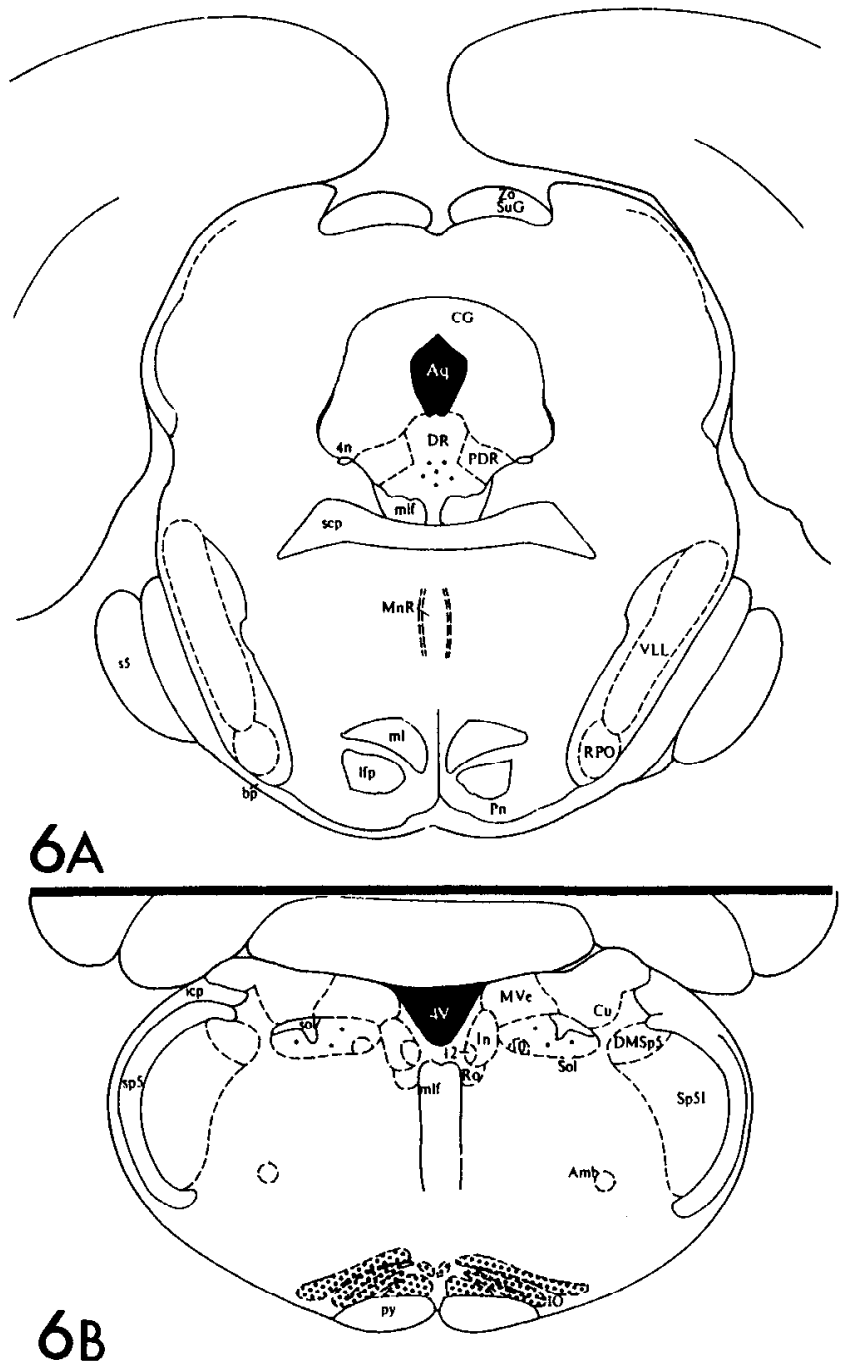

Figure 6. Schematic drawings of the distribution of immunoreactive puncta in the dorsal raphe nucleus $(D R)$ in $A$, and the IO and solitary nuclcus $(S o l)$ in $B$. Note that all olivary subdivisions contain a high density of immunoreactive puncta. Abbreviations are given in Table 2. Distance left to right equals $9.2 \mathrm{~mm}$ in $A$ and $7.2 \mathrm{~mm}$ in $B$. Rostrocaudal level in $A, 8.0 \mathrm{~mm} ; B, 13 \mathrm{~mm}$ posterior to bregma.

samples in different sections were averaged for each rat and subsequently averaged among all animals. According to differences in density, the areas were scparated into three groups: (1) areas with a density higher than five dots per $1000 \mu^{2} ;$ (2) areas with an intermediate density of 2-5 dots per $1000 \mu \mathrm{m}^{2}$; and (3) areas with a density lower than two dots per $1000 \mu \mathrm{m}^{2}$. We calculated the standard errors of the means (SEM) and statistically compared the data of the different brain areas as well as of the different olivary subnuclei by Student's $t$ test (Glantz, 1981).

\section{Electron microscopy}

Immunocytochemistry. Four adult Sprague-Dawley albino rats were anesthetized with sodium pentobarbital $(45 \mathrm{mg} / \mathrm{kg})$ and perfused transcardially with $200 \mathrm{ml}$ Ringer's solution saturated with $95 \% \mathrm{CO}_{2}$ and $5 \% \mathrm{O}_{2}$ to $\mathrm{pH} 7.1$, followed by 1 liter of $4 \%$ freshly depolymerized formaldehyde and $0.1 \%$ glutaraldehyde in $0.12 \mathrm{M}$ sodium phosphate buffer ( $\mathrm{pH} 7.4$, room temperature). The brains were removed $1 \mathrm{hr}$ after perfusion, rinsed in ice-cold Tris-buffered saline (TBS, $290 \mathrm{mOsm}, \mathrm{pH}$ 7.5), and cut coronally at $40 \mu \mathrm{m}$ on a Vibratome. The sections were rinsed in TBS with $0.05 \%$ Triton X (TBST) and subsequently blocked, incubated in the primary (the primaries included antiserum $\alpha 12 \mathrm{~B} / 18$ as well as antisera $\alpha 15, \alpha 16$, and $\alpha 18$ ), rinsed, incubated in goat anti-rabbit IgG (Sternberger-Meyer), rinsed, incubated in rabbit PAP (Sternberger-
Meyer), rinsed, and reacted in DAB and $\mathrm{H}_{2} \mathrm{O}_{2}$ as described for light microscopy, with the exception that TBST was used as a buffer. Finally, the sections containing areas with immunoreactivity were selected, rinsed in $0.12 \mathrm{M}$ phosphate buffer at $\mathrm{pH} 7.3(\mathrm{~PB})$, osmicated in $2 \%$ osmium tetroxide in $\mathrm{PB}$, thoroughly rinsed in $\mathrm{H}_{2} \mathrm{O}$, stained en bloc in $2 \%$ uranyl acetate in $\mathrm{H}_{2} \mathrm{O}$ overnight, dehydrated in alcohol and propylene oxide, and flat embedded in Araldite. Pyramids were made of all the areas with a high or intermediate density of immunoreactivity. U1trathin sections were cut on an LKB ultratome from the most superficial portions of these selected tissue blocks, collected on single-hole, Formvar-coated grids, counterstained with lead citrate, and examined on a Zeiss EM-10 electron microscope operating at $80 \mathrm{kV}$.

Standard EM. Two adult Sprague-Dawley albino rats, two adult Dutch belted rabbits, and two adult cats were used for standard EM to study, under optimal conditions, the cellular structures corresponding to the puncta. In the rats, we examined all the areas with a high or intermediate density of immunoreactivity uncovered in the material processed for immunocytochemistry, while in the rabbits and cats we studied only the IO. All animals were anesthetized with sodium pentobarbital $(45 \mathrm{mg} / \mathrm{kg}$ ) and perfused transcardially with $200-400 \mathrm{ml}$ of a Ringer's solution saturated with $95 \% \mathrm{CO}_{2}$ and $5 \% \mathrm{O}_{2}$ to $\mathrm{pH} 7.1$, followed by 1 (rat)-2 (rabbits and cats) liters of $2 \%$ freshly depolymerized formaldehyde and $1.5 \%$ glutaraldehyde in $0.12 \mathrm{M}$ sodium phosphate buffer ( $\mathrm{pH} 7.4$, room temperature). The brains were removed 1 $\mathrm{hr}$ after perfusion, rinsed in ice-cold TBS, and cut coronally at $200 \mu \mathrm{m}$ on a Vibratome. The slices were rinsed in PB, osmicated in $2 \%$ osmium tetroxide in $\mathrm{PB}$, or in ferrocyanide $(1.5 \%)$-reduced osmium tetroxide (1\%) according to Karnovsky (1971), rinsed in $\mathrm{H}_{2} \mathrm{O}$, and stained en bloc in $2 \%$ uranyl acetate in $\mathrm{H}_{2} \mathrm{O}$ overnight. Subsequently, the sections were rinsed in $\mathrm{H}_{2} \mathrm{O}$, dehydrated in alcohol and propylene oxide, and embedded in Araldite. Guided by observations in the semithin sections stained with toluidine blue, we made pyramids of the areas of interest. Ultrathin sections were cut, collected, counterstained with uranyl acetate and lead citrate, and examined in the EM.

\section{Results}

\section{Light microscopy}

Distribution of immunoreactivity. Brain sections from adult rats immunostained with antiserum $\alpha 12 \mathrm{~B} / 18$ presented punctate labeling in the neuropil of a restricted number of areas. The diameter of the puncta varied from approximately $0.2 \mu \mathrm{m}$ to 1.2 $\mu \mathrm{m}$. No labeled fibers or neurons were observed. The immunoreactive puncta occurred at varying densities in different regions: (1) at high densities ( $>5$ dots per $1000 \mu \mathrm{m}^{2}$ ) in the $\mathrm{IO}$, the stratum lacunosum moleculare (SLM) of area CA1 and CA3 along the ventral hippocampal fissure (HiF), and in the first layer of the piriform cortex along the entire lateral olfactory tract (Pirlo) (Figs. 1-6); (2) at intermediate densities (2-5 dots per 1000 $\left.\mu \mathrm{m}^{2}\right)$ in the polymorph layer of the dentate gyrus of the hippocampus (PoDG), and the external plexiform layer of the olfactory bulb (EplOB), (Figs. $2 B, 3 B$ ); and (3) at low densities $\left(<2\right.$ dots per $1000 \mu \mathrm{m}^{2}$ ) in the deep layers of the cerebral (especially the frontal, cingulate, agranular insular, and lateral orbital) cortex, stratum pyramidale, and stratum radiatum along the ventral HiF (area CA1 and CA3), peri- and paraventricular hypothalamus $(\mathrm{Pe})$, ventrolateral part of the supraoptic nucleus (SO), basolateral amygdaloid nucleus (BLA) and the surrounding amygdala (Amyg), accumbens nucleus (Acb), nucleus subparafascicularis of the thalamus (PF) and the adjacent area around the fasciculus retroflexus, ventral and dorsal endopiriform nucleus (VEn, DEn), dorsal raphe nucleus (DR), and solitary nucleus (Sol), (Figs. 2A, 4-6). Counts of the puncta in the brain areas with high and intermediate labeling densities are represented in a histogram in Figure $7 A$. The concentrations of puncta in the areas with a high density were significantly higher $(p<0.02)$ than those in the areas with an intermediate or low density. In addition, immunoreactive puncta were observed in 


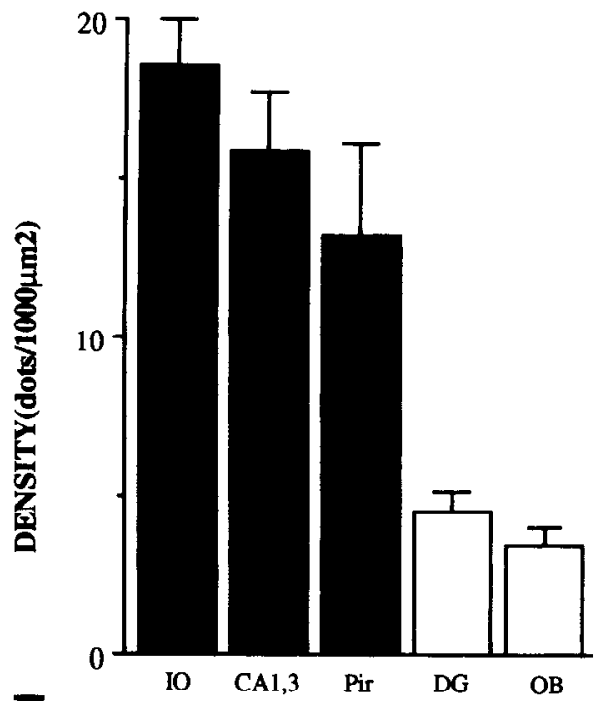

$7 \mathrm{~A}$

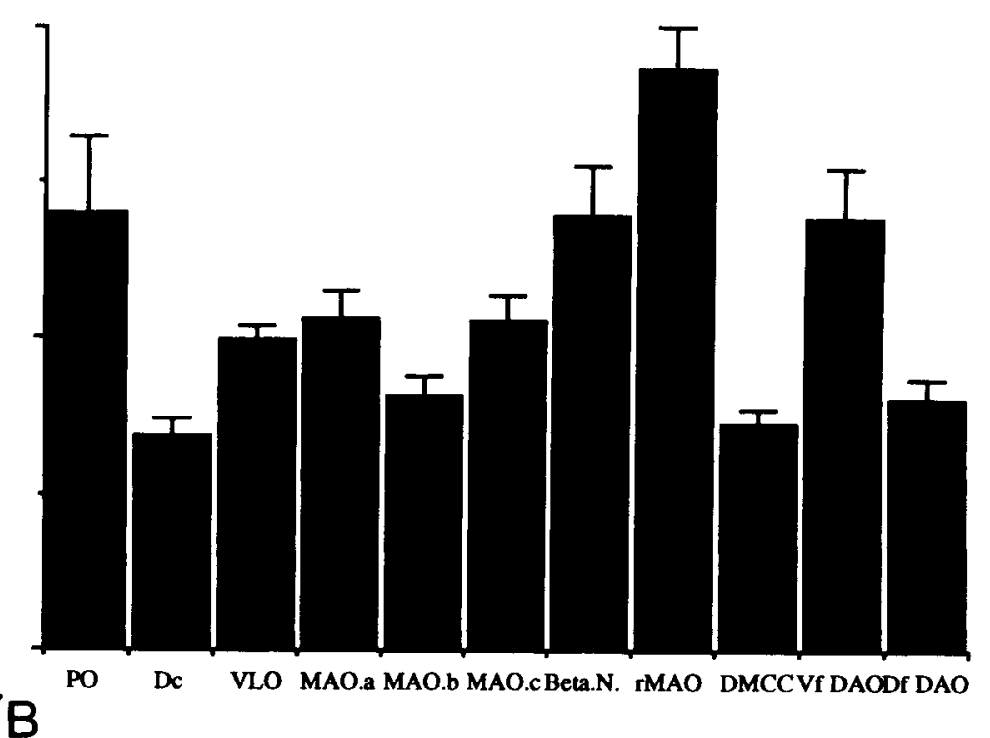

Figure 7. Histograms of the densities of immunoreactive puncta obtained with antiserum $\alpha 12 \mathrm{~B} / 18$ in different brain regions $(A)$ and different subdivisions of the IO $(B) . A$, Histograms of the brain regions classified as high (black columns; $>5$ immunoreactive dots per $1000 \mu \mathrm{m}^{2}$ ) or intermediate (white columns; 2-5 dots per $1000 \mu \mathrm{m}^{2}$ ) density areas. In all these regions the values were deternnined in the subdivision or layer with the highest density of puncta; that is, for the IO the rMAO; for CA1,3 the SLM along the ventral HiF; for the Pir layer I along the lateral olfactory tract; for the DG the polymorph layer; and for the OB the external plexiform layer. Total number of dots counted in all represented areas of all four rats is 61,349 . B , Histograms of the densities of immunoreactive puncta in the olivary subdivisions. Total number of dots counted in all given subdivisions of all four rats is 21,077 . Bars on top of the columns in $A$ and $B$ indicate SEMs.

the ependyma. These ependymal dots were somewhat more irregularly shaped than those in the neuropil.

In the IO the immunoreactive puncta were ubiquitously distributed in all its subnuclei. The rostral medial accessory olive (rMAO; 18.6 dots per $1000 \mu \mathrm{m}^{2}$ ) had the highest, and the dorsal cap (Dc; 6.8 dots per $1000 \mu \mathrm{m}^{2}$ ) the lowest density. The density of immunoreactive puncta in the rMAO was significantly higher $(p<0.05)$ than in the $\mathrm{Dc}$, ventrolateral outgrowth (VLO), subnuclci $\mathrm{a}, \mathrm{b}$, and $\mathrm{c}$ of the caudal MAO, the dorsal medial cell column (DMCC), and the dorsal fold of the dorsal accessory olive (DfDAO; for exact densities of all olivary subnuclei, see Fig. $7 B$ ). Within the IO, differences in sizes of the puncta were approximately proportional to the densities of puncta in the subnuclei; for example, the dots in the rMAO were rather large (Fig. $1 B$ ) and in the Dc relatively small (see also electron micrographs in botton portion of Figs. 10B, 11). In other areas in the brain, however, this correlation did not hold true; for example, the puncta in the PoDG were large, whereas the puncta in the HiF were more variable and on average smaller (for light micrographs see Fig. 2, for electron micrographs see Figs. 9B, C, 12C, 13).

At P9 the rat IO showed little immunoreactivity, whereas at P15 labeled puncta were clearly present (Fig. $1 C$ ). The density at P15 was 5.9 dots per $1000 \mu \mathrm{m}^{2}$.

Antibody specificity. The brain sections processed with the preimmune serum did not show any immunoreactivity. However, antiserum $\alpha 12 \mathrm{~B} / 18$ preabsorbed with the synthetic peptide $\alpha 12 \mathrm{~B}$ and/or its carrier BSA provided the same immunoreactivity on the sections as the nonpreabsorbed antiserum. Therefore, we undertook affinity puritication of the antibody of antiserum $\alpha 12 \mathrm{~B} /$ 18 that recognizes peptide $\alpha 12 \mathrm{~B}$. The affinity-purified antibody of antiserum $\alpha 12 \mathrm{~B} / 18$ did not provide the immunoreactive puncta revealed by the crude serum $\alpha 12 B / 18$, whereas the unbound fraction of the purified solution did immunolabel the same puncta. In the ELISA of the fractions that bound and eluted versus those that comprised the void volume, the purified antibody at dilutions higher than 1:800 showed an absorbance value that was more than 15 times the absorbance value of the void, suggesting relatively complete absorption of the anti-peptide $\alpha 12 \mathrm{~B}$ activity. The Western immunoblots of homogenates of the $\mathrm{IO}, \mathrm{HiF}$, and Pirlo made with antiserum unbound to the peptide $\alpha 12 \mathrm{~B}$ affinity column showed a triplet of dominant bands at $110-140 \mathrm{kDa}$ (Fig. 8A); in the blot of the IO the $140 \mathrm{kDa}$ band dominated, whereas in the blots of the HiF and the Pirlo the other two bands were most prominent. All three bands were absent in the blots of the residual brain. In contrast, all Western immunoblots made with the use of the affinity-purified antibody of antiserum $\alpha 12 \mathrm{~B} /$ 18 showed a positively labeled $43 \mathrm{kDa}$ band (Fig. $8 B$ ). Blots made with the use of the preimmune serum were essentially negative. Hence, during the course of immunization, antibodies arose whose specificity for dendritic lamellar bodies correlated the development of binding to three positive bands in the 110$140 \mathrm{kDa}$ range.

Antibodies $(\alpha 15, \alpha 16$, and $\alpha 18)$ to other peptides corresponding to regions of $\mathrm{Cx} 43 \mathrm{did}$ not provide the typical immunoreactive puncta revealed by antiserum $\alpha 12 \mathrm{~B} / 18$. The sections of the heart muscle of the rat, which were processed for immunocytochemistry simultaneously with the brain sections, showed characteristic gap junction labeling with antibodies to peptides $\alpha 16$ and $\alpha 18$, which are cytoplasmic determinants expected to be accessible to antibodies (see also Yancey et al., 1989). However, the heart sections processed with the antisera to peptides $\alpha 12 \mathrm{~B}$ and $\alpha 15$, that is, sequences of, respectively, the first and second extracellular loop of $\mathrm{Cx} 43$, did not show any immunoreactivity.

\section{Electron microscopy}

Ultrastructural analysis of the immunoreactive puncta revealed by antiserum $\alpha 12 \mathrm{~B} / 18$ in the areas with a high or intermediate density of labeling (i.e., IO, SLM along the ventral HiF, Pirlo, 

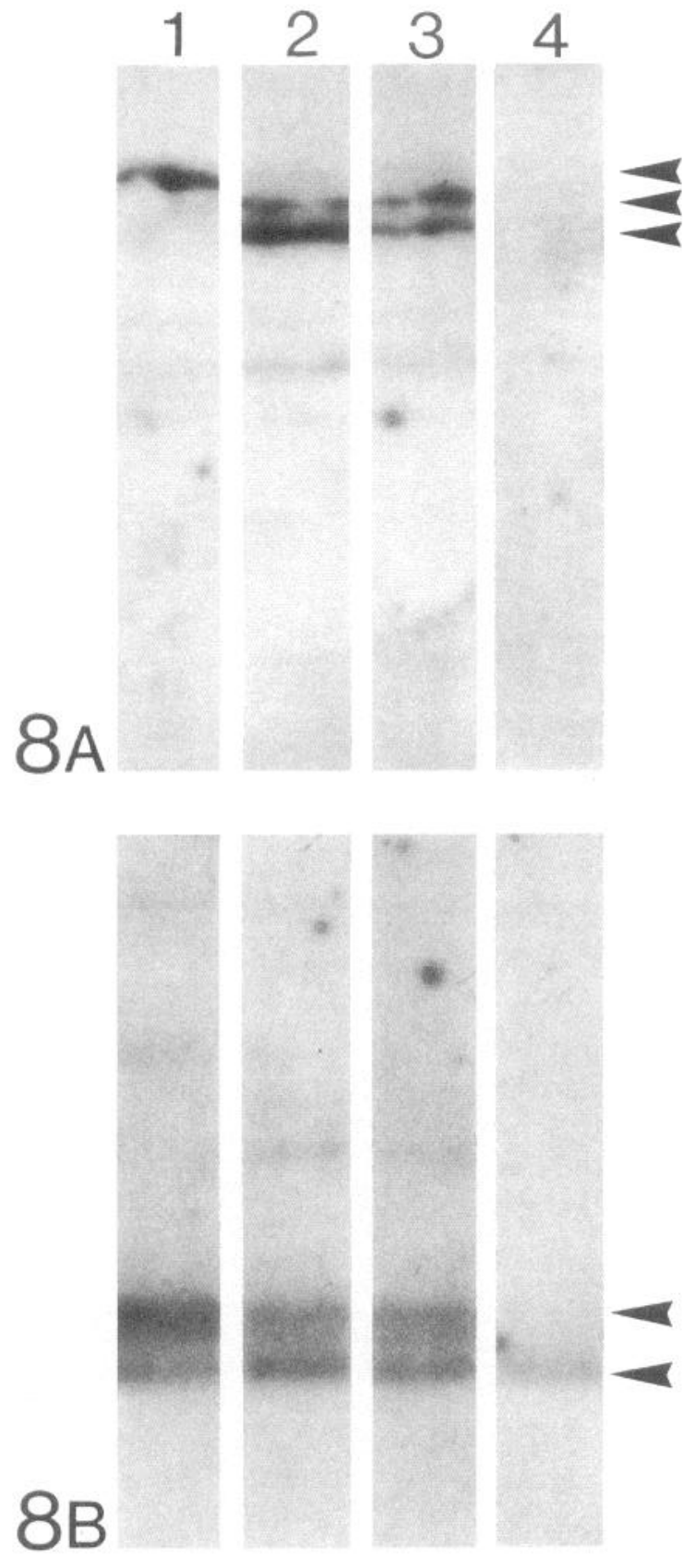

Figure 8. Western blots of the IO (lane 1), HiF (lane 2), Pirlo (lane 3 ), or residual brain (lane 4) were probed either with antiserum unbound to the peptide $\alpha 12 \mathrm{~B}$ affinity column $(A)$ or with antiserum specific for this amino acid sequence (49-61 of rat $\mathrm{Cx} 43$ ) eluted at $\mathrm{pH} 2.1$ and rapidly neutralized prior to use $(B)$. Fifty micrograms of protein from these dissected areas were loaded on each lane prior to SDS-PAGE. A, The three arrowheads indicate the location of the three prominently immunostained proteins with molecular weights estimated from 110 to $140 \mathrm{kDa}$ (bottom to top). Note the lack of immunostaining in lane 4, presumably as a result of enrichment for the corresponding protein(s) in the dissected fractions. $B$, Immunostaining was observed to a doublet of $41-43 \mathrm{kDa}$ bands which represent its unphosphorylated and phosphorylated bands, respectively (Musil et al., 1990). It should be noted that the predominance of the unphosphorylated form of $\mathrm{Cx} 43$ in lane 4 is likely to be due to post-mortem dephosphorylation of $\mathrm{Cx} 43$ (Hossain et al., 1994).
PoDG, and EplOB) showed that a new cellular organelle was labeled, which was exclusively located in bulbous dendritic appendages (Figs. 9, 10A). In all the examined brain areas, no other cellular structures like glial or neuronal gap junctions, ER, or spine apparatuses were labeled. The organelle consisted of a group of cisternae formed by lamellae made of smooth membranes (Figs. 10B, 11-13), and will be referred to as "dendritic lamellar body" (DLB). In between the cisternae some electrondense material was present. The immunoprecipitate was situated in both the membranes of the lamellae and the electron-dense material, but was absent in the lumen of the cisternae (Fig. 10). The lamellae were up to $0.95 \mu \mathrm{m}$ long and had a thickness varying from 30 to $60 \mathrm{~nm}$ that was consistent along the entire length. The number of lamellae in individual organelles varied from 1 to 13. The number of lamellae depended on the brain area, and coincided with the differences in diameters of the immunoreactive puncta in the light microscope (e.g., for PoDG, compare size of the puncta in Fig. $2 B$ with number of lamellae in Figs. $12 C, 13 B$ ). Even when their number was high, the lamellae were closely grouped together with a regular interlamellar space of approximately $20 \mathrm{~nm}$. The lamellae were often curved and frequently surrounded partially or entirely a mitochondrion (Figs. 9, 13B). The lamellar cisternae were occasionally continuous with tubules of smooth ER (Fig. 12A); ribosomes were not associated with the lamellar body. DLBs were not surrounded by a common membrane, but sometimes one cisterna on the side of the DLB gave rise to multiple cisternae that formed the bulk of the organelle (Fig. 13A). The bulbous dendritic appendages with DLBs usually contained mitochondria and lacked microtubules and neurofilaments (Figs. 10B, 11-13), and they were sometimes found to originate from the parent dendritic stems by rather thin and long stalks (Fig. 12A,C). Mostly they were surrounded by astrocytic processes, but infrequently axon terminals established symmetric or asymmetric synapses with these appendages (Figs. 11B, 13A). Neither in the material processed for immuno-EM nor in the standard EM material were bodies resembling DLBs observed in cell bodies or neuronal structures other than dendrites. In rat, we never found more than one DLB in a single bulbous appendage.

In the neuropil of all the subnuclei of the IO, as well as in the Pirlo, PoDG, and EplOB, dendrodendritic gap junctions were observed. These gap junctions predominantly linked spiny appendages that were smaller than the bulbous appendages with the DLBs. In nonserial sections of the IO the ratio of the number of dendrodendritic gap junctions to the number of DLBs was close to $1(0.93 ; n$ DLBs $=107)$. A DLB was never seen in close proximity to a dendrodendritic gap junction in the same electron micrograph. However, serial section analysis of olivary dendrites showed that the spiny appendages connected with the bulbous appendage containing a DLB could form gap junctions; the shortest distance measured between a DLB and a gap junction was approximately $5 \mu \mathrm{m}$ (see Fig. 14). The same serial section analysis also demonstrated that DLBs occur only in a minority of the bulbous appendages. In the SLM along the ventral HiF we observed many specialized dendritic appositions at which the membranes approached much closer to each other than the normal $20 \mathrm{~nm}$, but we did not find the heptalaminar membranous organization characteristic of neuronal gap junctions.

DLBs were also present in standard EM material of the IO of the rabbit and the cat (Fig. 11). In these animals DLBs had the same morphological features and were also exclusively located 

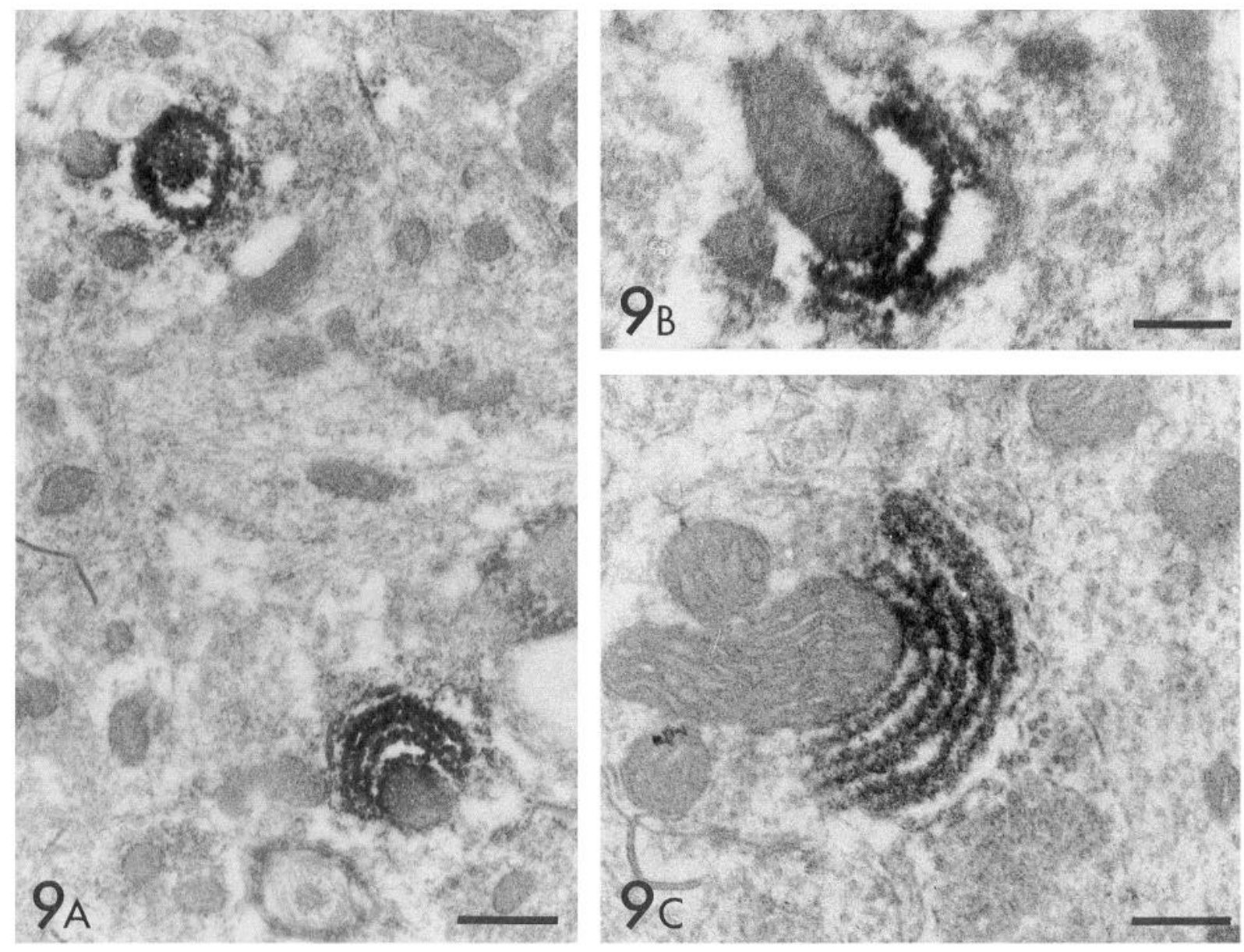

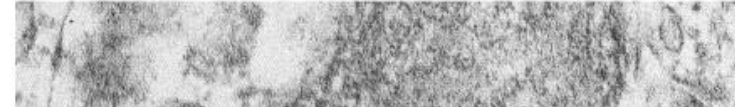

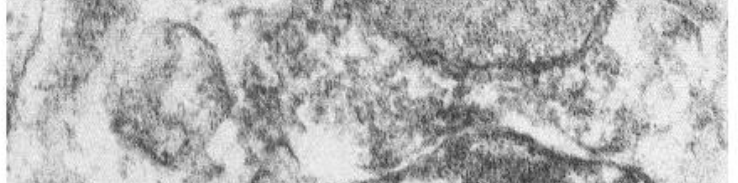

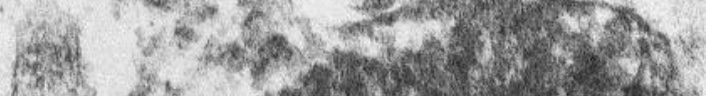

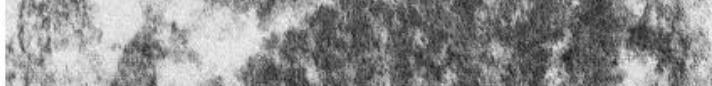

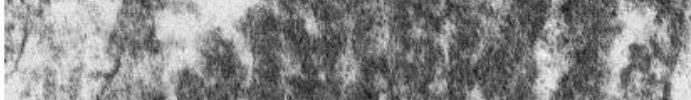

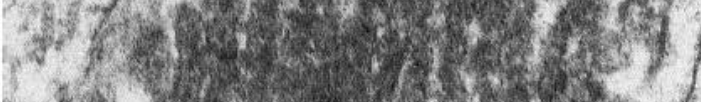

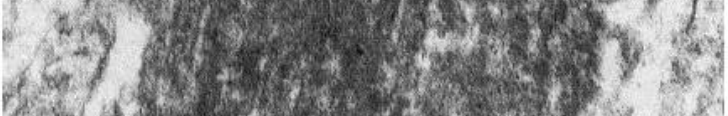

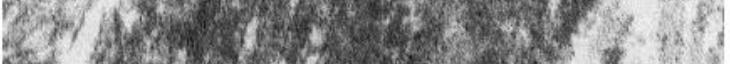

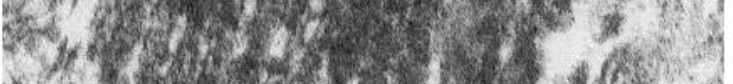

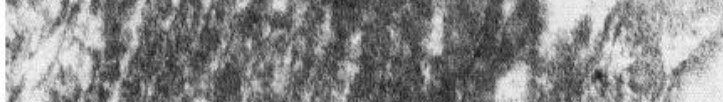

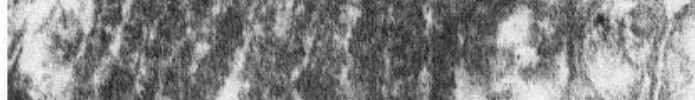

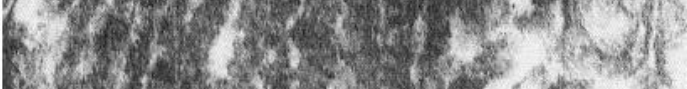

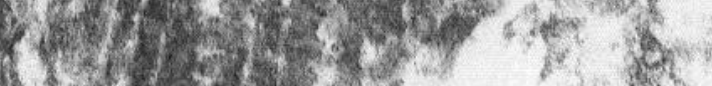
i.

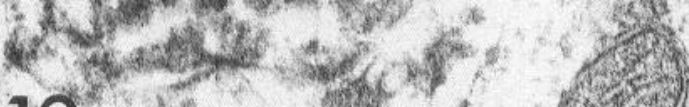
$10 A+10 \times-10$

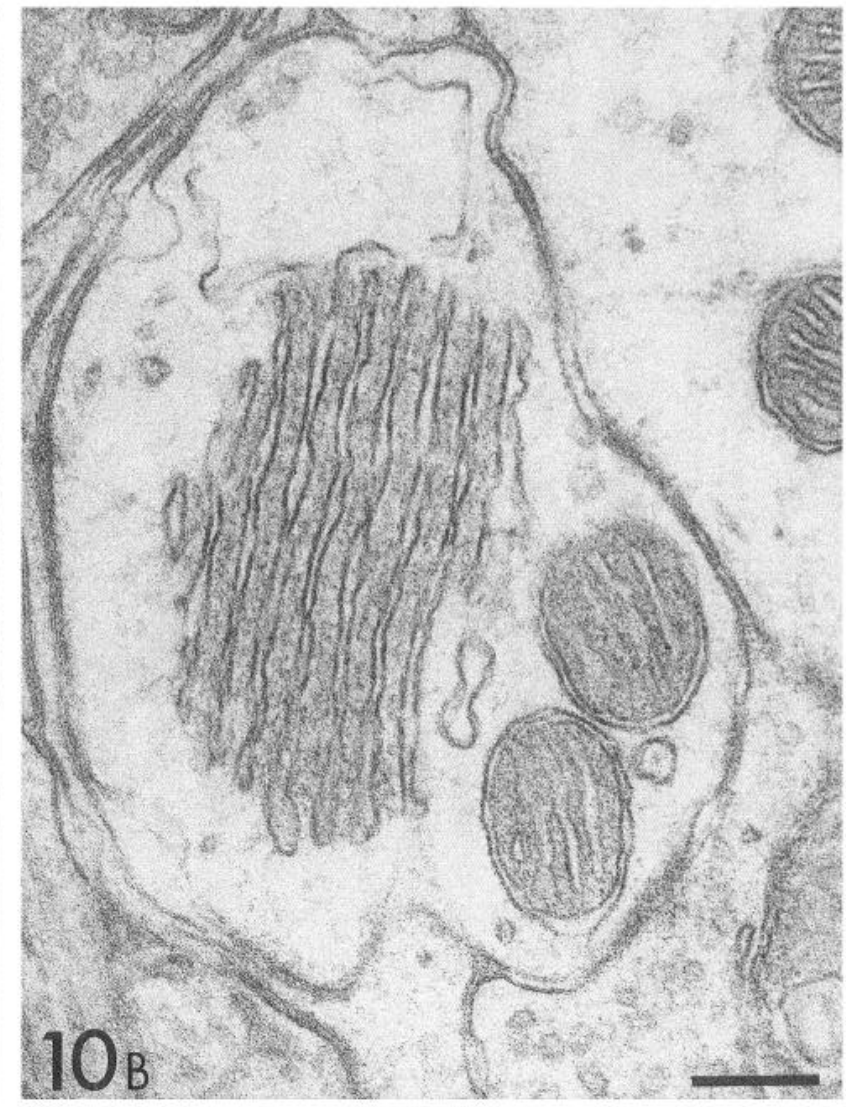


in dendritic appendages. In cat, we observed one dendritic appendage that contained two DLBs. Neither in the rat nor in the rabbit and the cat did we observe two apposed dendritic elements that both contained a DLB.

Antisera $\alpha 15, \alpha 16$, and $\alpha 18$ did not label the dendritic lamellar bodies labeled by antiserum $\alpha 12 \mathrm{~B} / 18$.

\section{Discussion}

In the present study, we describe a new organelle, named the dendritic lamellar body (DLB), which can be specifically labeled utilizing a new antiserum. Below, we will discuss the specificity of the antiserum as well as the morphological characteristics of the organclle and its relation with neuronal gap junctions.

\section{Antibody specificity}

Antiserum $\alpha 12 \mathrm{~B} / 18$ provided a specific immunoreactivity since all immunoreactive puncta in the examined brain areas corresponded to DLBs. However, it is not clear what peptide(s) is labeled in the DLBs by $\alpha 12 \mathrm{~B} / 18$. First, $\alpha 12 \mathrm{~B} / 18$ preabsorbed with peptide $\alpha 12 \mathrm{~B}$ provided the same immunoreactivity as the nonpreabsorbed antiserum. Second, the affinity-purified antibody of $\alpha 12 \mathrm{~B} / 18$ prepared with $\alpha 12 \mathrm{~B}$ linked to the matrix did not provide the immunoreactive puncta, whereas the unbound fraction of the purified solution did. These data suggest that peptide $\alpha 12 B$ is not present in the DLBs.

On the other hand, the ELISA showed a strong binding between antiserum $\alpha 12 B / 18$ and peptide $\alpha 12 B$, and the Western immunoblots of brain homogenates made with the affinity-purificd antibody provided a positively labeled $43 \mathrm{kDa}$ band, indicating that antiserum $\alpha 12 B / 18$ can detect peptide $\alpha 12 B$. Since peptide $\alpha 12 \mathrm{~B}$ is part of $\mathrm{Cx} 43$ (Beyer et al., 1987; Fishman et al., 1990; Kumar and Gilula, 1992) and since most antisera against other parts of $\mathrm{Cx} 43$ label gap junctions between glia, ependymal, pial, and/or arachnoid cells (Beyer et al., 1987; Nagy et al., 1989; Yancey et al., 1989; Yamamoto et al., 1990a; Dermietzel et al., 1991), the above findings raise the question of why there was no labeling of gap junctions in the brain or heart with the use of $\alpha 12 \mathrm{~B} / 18$. This absence of labeling may be due to the fact that peptide $\alpha 12 \mathrm{~B}$ cannot be detected if $\mathrm{Cx} 43$ is incorporated in the intact gap junction channel. Peptide $\alpha 12 \mathrm{~B}$ is part of the first of the two extracellular loops of $\mathrm{Cx} 43$ (Kumar and Gilula, 1992) that are intramolecularly, noncovalently linked to one another by disulfide bonds (John and Revel, 1991). Similarly, the antiserum raised against peptide $\alpha 15$, which is part of the second extracellular loop, did not provide any gap junction labeling either. Moreover, the extracellular loops of connexins of apposing cells are connected together to form a functional gap junction channel (Kumar and Gilula, 1992). Since peptide $\alpha 12 B$ is positioned in the middle of the extracellular loop, it is probably also involved in this intermolecular linkage.

The finding that antiserum $\alpha 12 \mathrm{~B} / 18$ may not label $\mathrm{Cx} 43$ in the intact gap junction channel due to steric hindrance does not mean that $\mathrm{Cx} 43$ is present in the DLBs. The fact that antisera $\alpha 16$ and $\alpha 18$, which are raised against cytoplasmic parts of Cx43, did not label the DLBs either suggests that Cx43 is absent in DLBs.

Because the sections processed with preimmune serum did not show any immunoreactivity, it is possible that antiserum $\alpha 12 \mathrm{~B} /$ 18 cross-reacts with a peptide similar to $\alpha 12 \mathrm{~B}$, which is known to be highly preserved among different connexin families $(\mathrm{Ku}-$ mar and Gilula, 1992). We cannot exclude that the 110-140 kDa bands in the Western immunoblot correspond to a presently unknown connexin family. In this respect, it should be noted that gap junction hemichannels can probably be constructed from different types of connexin subunits (Hoh et al., 1993; Evans, 1994).

\section{Comparison with other connexin markers}

Most of the brain areas that showed immunoreactive puncta with $\alpha 12 \mathrm{~B} / 18$ were also labeled in studies in which antibodies against parts of $\mathrm{Cx} 27$ and $\mathrm{Cx} 32$, or against other parts of $\mathrm{Cx} 43$, were applied (Nagy et al., 1988; Shiosaka et al., 1989; Yamamoto et al., 1989a, 1990a,c). In addition, the distribution of immunoreactivity with $\alpha 12 \mathrm{~B} / 18$ largely coincides with the distribution of Cx43 mRNA and Cx32 mRNA (Naus et al., 1990; Matsumoto et al., 1991; Micevych and Abelson, 1991). However, $\alpha 12 \mathrm{~B} / 18$ differs from other markers in that it provides labeling in a more restricted number of brain areas. Moreover, $\alpha 12 B / 18$ is the only "gap junction-related" marker, at present, that labels neuronal, but no glial, profiles. Therefore, by demonstrating DLBs, $\alpha 12 B /$ 18 may indicate more specifically than other markers the distribution of neuronal gap junctions in the brain.

\section{Morphological characteristics}

Ultrastructural analysis of the IO, HiF, Pirlo, PoDG, and EplOB showed that the DLB consists of a varying number of regularly interspaced lamellae situated in the cytoplasm of bulbous dendritic appendages.

The DLB resembles somewhat the spine apparatus (Gray, 1959; Gray and Guillery, 1963; Peters et al., 1970). Spine apparatuses are composed of arrays of flattened cisternae separated by plaques of dense material. They have been observed in dendritic spines in neurons of the hippocampus (Hamlyn, 1962; Westrum and Blackstad, 1962; Blackstad, 1967), cerebral cortex (Peters et al., 1970), and IO (Gwyn et al., 1977; Rutherford and Gwyn, 1980). Several findings indicate that the DLB is different from a spine apparatus: (1) we have observed labeled DLBs and nonlabeled spine apparatuses in the same ultrathin sections of immunoreacted tissue of the hippocampus; (2) the DLBs usually contained more lamellae than the spine apparatuses; and (3) the vast majority of the DLBs were located in dendritic appendages larger than spines.

DLBs may be related to the Golgi apparatus or smooth ER because the cisternae of the DLB and ER were occasionally

$\leftarrow$

Figure 9. Electron micrographs of DLBs in the PO of the IO $(A)$, in the SLM along the ventral HiF $(B)$ and PoDG $(C)$ with the use of antibody $\alpha 12 \mathrm{~B} / 18$. In $A$, the DLB in the upper left consists of two tangentially cut lamellas, while the DLB at the bottom consists of four lamellas that are sectioned perpendicularly to this plane. Note that one of the DLBs in $A$ as well as the DLBs in $B$ and $C$ curve around a mitochondrion. Scale bars: $A, 0.49 \mu \mathrm{m} ; B, 0.26 \mu \mathrm{m} ; C, 0.27 \mu \mathrm{m}$.

Figure 10. A labeled DLB in the rat Pirlo $(A)$ and a nonlabeled DLB in the rMAO of the rat IO $(B)$ taken at the same magnification. Note that the immunoreaction product in $A$ corresponds to the membranes of the lamellae that form the cisternae as well as to the electron-dense material between the cisternae; the lumen of the cisternae, on the other hand, contains hardly any immunoprecipitate. In $B$ (taken from standard EM material), an axon terminal establishes a synapse with a dendritic appendage that contains a DLB (bottom right). Scale bars: $A$ and $B, 0.29 \mu \mathrm{m}$. 

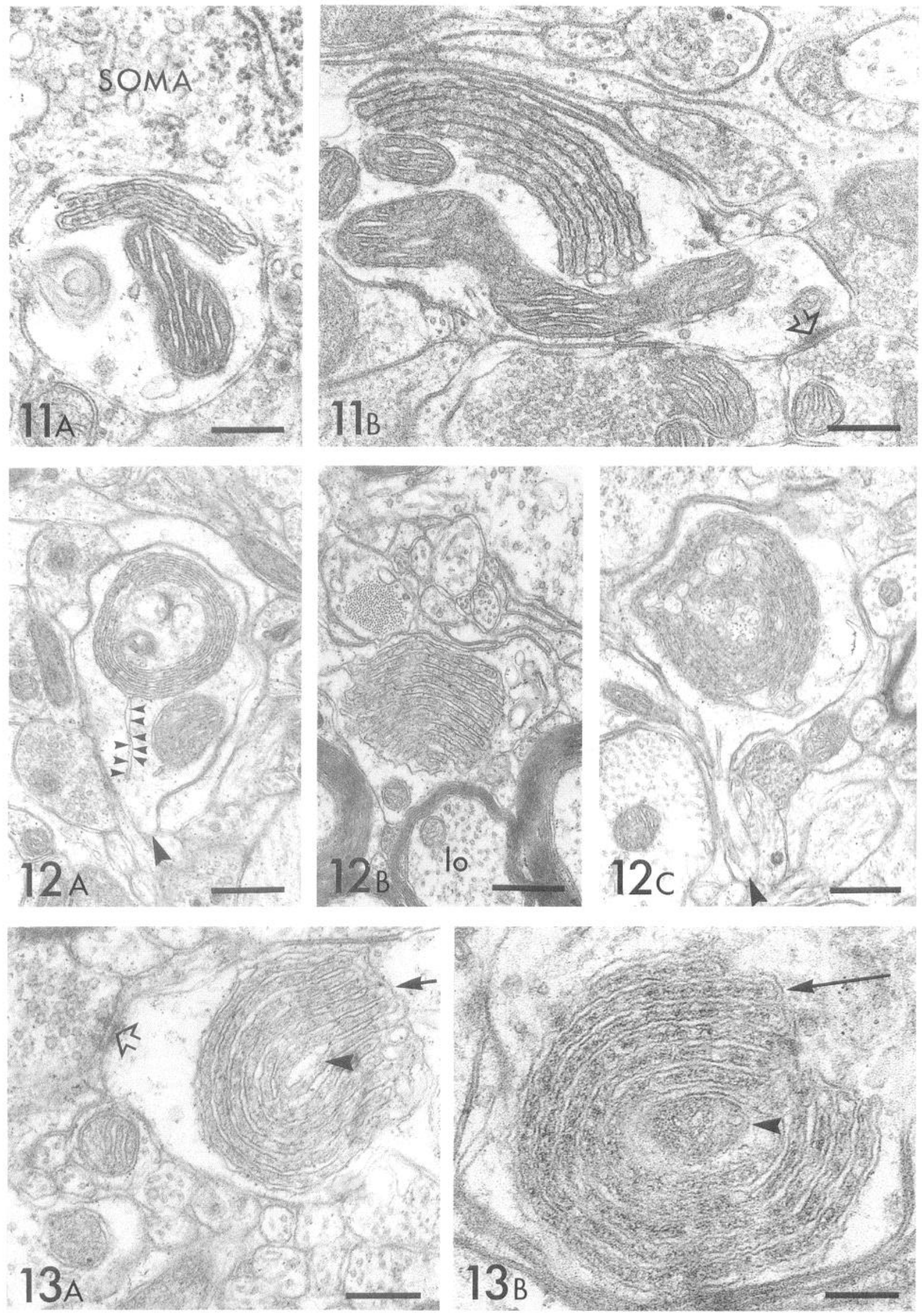

$13 B$ 
continuous with one another. The ER has also been found to be continuous with other structures like the nuclear envelope (Watson, 1955; Peters et al., 1970), subsurface cisterns of C-type terminals on motoneuronal perikarya (Yamamoto et al., 1989b, 1990b, 1991), and the laminated body (Morales et al., 1964). The laminated body has been observed in the lateral geniculate nucleus (Morales et al., 1964; Peters and Palay, 1966), striate cortex (Kruger and Maxwell, 1969), and cerebellar cortex (Morales and Duncan, 1966; Mugnaini, 1972). These structures cannot be confused with the DLBs since they consist of tubules embedded in a dense matrix, they are up to $5 \mu \mathrm{m}$ in diameter, and they occur only in perikarya.

In all examined brain areas, the DLBs were located in thick bulbous appendages. These appendages, which originated from dendritic stems and received synaptic inputs, can be considered as specialized portions of the dendritic arbors. From what type of neurons these dendrites with DLBs originate was not determined in the present study. In the IO, they are probably projection neurons that provide climbing fibers to the cerebellum (Szentágothai and Rajkovits, 1959; Eccles et al., 1966; Desclin, 1974), because these neurons have thick dendritic appendages (Ruigrok et al., 1990; De Zeeuw et al., 1990a) and because olivary interneurons are scarce (Fredette et al., 1992). In the Pirlo and in the SLM along the ventral HiF, the dendrites with appendages containing DLBs probably originate from pyramidal cells, because the dendritic plexi formed by ramifications of apical dendrites of these cells are located in these areas, and because these regions contain few dendrites from other neurons (Ramón y Cajal, 1909, 1911; Valverde, 1965; Blackstad, 1967; Somogyi et al., 1984; Wouterlood et al., 1985). Finally, in the PoDG and EplOB the most likely, although not the only, candidate to give rise to dendritic appendages with DLBs is the granular cell (see also Ramón y Cajal, 1909, 1911; Landis et al., 1974; MacVicar and Dudek, 1982; Shepherd, 1990).

\section{Correlation lamellar bodies and neuronal gap junctions}

In the mammalian brain, there are few areas where electrotonic coupling and/or neuronal gap junctions have been firmly demonstrated (for summary see Table 1). Coupling by gap junctions is probably more conspicuous in the IO than any other area (for cats, see Sotelo et al., 1974; Llinás et al., 1974; De Zeeuw et al., 1989, 1990a; primates, Rutherford and Gwyn, 1977; rats, Gwyn et al., 1977; Angaut and Sotelo, 1989; Lang et al., 1989, 1990; Llinás and Sasaki, 1989; De Zeeuw et al., 1990b; opossum, King, 1980; guinea pigs, Llinás and Yarom, 1981; Benardo and Foster, 1986; rabbits, De Zeeuw et al., 1993; Wylie et al., 1993). The present observation that an antiserum "raised against a gap junction protein" provided a high density of immunoreactive puncta in all subnuclei of the IO suggests that the DLBs may be related to ncuronal gap junctions.

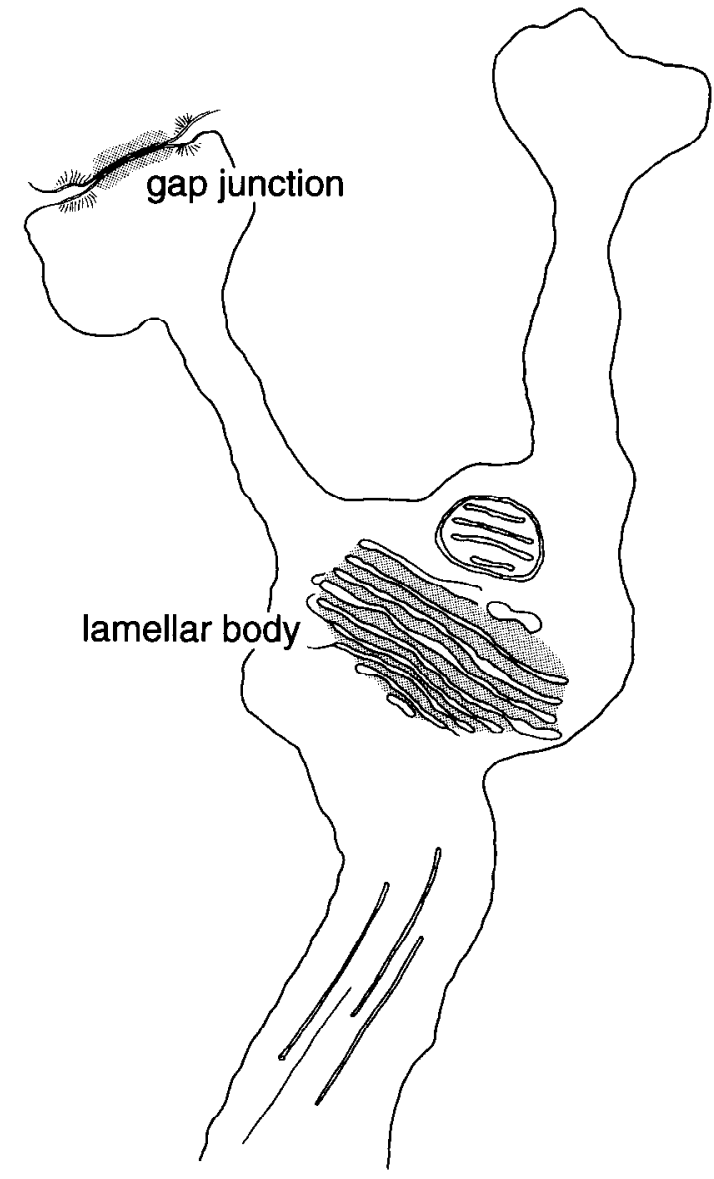

Figure 14. Drawing of a serial reconstruction of a portion of a dendrite containing a DLB in the IO of the rat (EM data published elsewhere). The bulbous appendage with the DLB does not contain a gap junction while the dendritic spine originating from that dendrite does. Note also that the appendage with the DLB does not contain any microtubules or neurofilaments, whereas the dendrite that gives rise to this appendage does contain these neuronal elements.

This possible correlation is supported by several other findings. First, the developmental study of young rats showed that antiserum $\alpha 12 \mathrm{~B} / 18$ provides the first immunoreactivity between P9 and P15. This period coincides with the appearance of neuronal gap junctions in the IO (Bourrat and Sotelo, 1983). Second, the density of immunoreactive puncta is highest in the rMAO. Llinás and Yarom (1981) demonstrated by simultaneous impalement of neuron pairs in the IO that electrotonic coupling is more prominent in this subdivision than in other olivary subnuclei. The correlation is further strengthened by the fact that coupling and/or ncuronal gap junctions are present in regions

Figure 11. DLBs in the IO of the rabbit $(A)$ and the cat $(B)$. The small organelle in $A$ is located in a dendritic appendage apposed to a soma in the De, while the larger organelle in $B$ is located in an appendage in the rMAO. The arrow in $B$ indicates an asymmetric synapse. Scalc bars: $A$, $0.34 \mu \mathrm{m} ; B, 0.47 \mu \mathrm{m}$.

Figure 12. DLBs in the OB $(A)$, Pirlo $(B)$, and PoDG $(C)$. In $A$, the DLB is continuous with a tubule of smooth ER (small arrowheads). In $B$, the DLB is located at the border of the lo and the first layer of the Pir. Note that the appendages in $A$ and $C$ originate from dendritic stalks (large arrowheads). Scale bars: $A, 0.65 \mu \mathrm{m} ; B, 0.60 \mu \mathrm{m} ; C, 0.68 \mu \mathrm{m}$.

Figure 13. Large horseshoe-shaped DLBs in the SLM along the ventral HiF $(A)$ and PoDG $(B)$ of the rat. In $A$, the center of the organelle (arrowhead) is empty and the beginning of the different lamellae is formed by a common cisterna (arrow), whereas in $B$ the center is filled by a mitochondrion (arrowhead) and there is no common cisterna (arrow). Open arrow indicates an asymmetric synapse. Scale bars: $A, 0.36 \mu \mathrm{m} ; B$, $0.27 \mu \mathrm{m}$. 
Table 1. Distribution of DLBs and predominant type of neuronal gap junctions in different areas of the mammalian nervous system

\begin{tabular}{|c|c|c|c|}
\hline Areas & $\begin{array}{l}\text { Lam. } \\
\text { bodies }\end{array}$ & Gap junctions & References \\
\hline IO & +++ & Dendrodendritic & Sotelo et al., 1974; De Zeeuw et al., 1989 \\
\hline Layer I Pirlo & +++ & Dendrodendritic & Present study \\
\hline PoDG & ++ & Dendrodendritic & MacVicar and Dudek, 1982 \\
\hline Epl of the OB & ++ & Dendrodendritic & Landis et al., 1974 \\
\hline Layers IV and V of cerebral cortex & + & Dendrodendritic & Sloper, 1972; Peters, 1980 \\
\hline $\mathrm{Pe}$ & + & Dendrodendritic & Andrew et al., 1981; Cobbett et al., 1985 \\
\hline SO & + & Dendrodendritic & Andrew et al., 1981 \\
\hline $\mathrm{PF}$ & + & $?$ & \\
\hline Amyg & + & $?$ & \\
\hline $\mathrm{Acb}$ & + & $?$ & \\
\hline VEn and DEn & + & $?$ & \\
\hline Igl of the OB & - & Somatosomatic & Reyher et al., 1991 \\
\hline VC & - & Somatosomatic & Sotelo et al., 1976 \\
\hline $\mathrm{DC}$ & - & Dendrosomatic & Wouterlood et al., 1984 \\
\hline Molecular layer cerebellum & - & Dendrosomatic & Sotelo and Llinás, 1972 \\
\hline SNB & - & Dendrosomatic & Matsumoto et al., 1988 \\
\hline DLN & - & Dendrosomatic & Matsumoto et al., 1989 \\
\hline
\end{tabular}

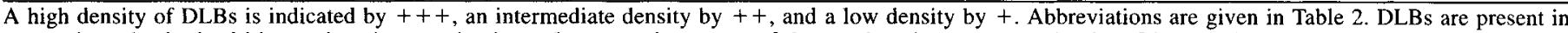
areas where dendrodendritic gap junctions predominate. In areas where most of the gap junctions are somatic, the DLBs are absent.

containing DLBs. These regions include the Pirlo and the PoDG (MacVicar and Dudek, 1982; present study), EPL of the OB (Landis et al., 1974), pyramidal cell layer and stratum radiatum of area CA1 and CA3 (MacVicar and Dudek, 1980, 1981; MacVicar et al., 1982; Church and Baimbridge, 1991; Matsumoto et al., 1991), layer IV and V of the cerebral cortex (Sloper, 1972; Smith and Moskovitz, 1979; Peters, 1980; Connors et al., 1983), and Pe and SO of the hypothalamus (Andrew et al., 1981; Cobbett et al., 1985). In the SLM of area CA1 and CA3 along the ventral $\mathrm{HiF}$ we were unable to detect gap junctions despite the fact that this area contains a high density of DLBs. However, these appendages are probably derived from apical dendrites of pyramidal cells which are electrotonically coupled in the stratum pyramidale and stratum radiatum (MacVicar and Dudek, 1980, 1981).

Neuronal gap junctions have also been observed in areas of the mammalian nervous system which do not contain DLBs (see Table 1). These areas include the lateral vestibular nucleus (LVe; Sotelo and Palay, 1970), mesencephalic trigeminal nucleus (Me5; Hinrichsen and Larramendi, 1968, 1970; Baker and Llinás, 1971), internal granular layer (Igl) of the OB (Reyher et al., 1991), molecular layer of the cerebellar cortex (Sotelo and Llinás, 1972), dorsolateral nucleus of the spinal cord (Matsumoto et al., 1989), spinal nucleus of the bulbocavernosus (Matsumoto et al., 1988), ventral cochlear nucleus (VC; Sotelo et al., 1976), and dorsal cochlear nucleus (DC; Wouterlood et al., 1984). The predominant types of neuronal gap junctions in these areas are axosomatic ( $\mathrm{LVe}$ ), somatosomatic (Me5, VC, and IglOB), and dendrosomatic (cerebellar cortex, SNB, DLN, and DC). In contrast, the gap junctions that are present in the areas where DLBs occur are predominantly dendrodendritic. Thus, in line with the finding that the DLBs were exclusively located in dendritic appendages, it seems likely that DLBs can be associated only with dendrodendritic gap junctions.

The ratio of the number of dendrodendritic gap junctions to the number of DLBs in the IO was close to 1 . However, since the interneuronal space of a gap junction $(2 \mathrm{~nm})$ is much smaller than the thickness of an ultrathin section $(50 \mathrm{~nm})$, the characteristic heptalaminar structure of a gap junction will be evident only if the ultrathin section is cut perfectly perpendicular to the gap junction plaque. Therefore, the number of gap junctions observed in the electron microscope must be a substantial underestimation of the actual number, and the number of DLBs in the IO must be substantially less than the actual number of gap junctions. This putative difference corresponds well with the difference in the number of bulbous and spiny appendages of the olivary dendrites. Reexamination of olivary neurons intracellularly injected with horseradish peroxidase (De Zeeuw et al., 1990a; Ruigrok et al., 1990) indicated that individual olivary dendrites contain approximately 10-40 bulbous appendages, 510 of which may include a DLB. The same individual dendrites also give rise to many more spiny appendages (often more than 100); these appendages are smaller than the bulbous ones and they are the appendages that form the bulk of the gap junctions in the IO (Sotelo et al., 1974; De Zeeuw et al., 1989). Thus, if, as hypothesized, the DLBs are somehow involved in the synthesis of gap junctions, then an individual DLB in a bulbous appendage probably serves many gap junctions located distally in the smaller spiny appendages (scc also Fig. 14).

One can only speculate on the function of the lamellar body at this point. It seems quite possible, for example, that the organelle is involved in the subunit assembly, which results in the 


\section{Table 2. List of abbreviated structures}

\begin{tabular}{|c|c|}
\hline $3 \mathrm{~V}$ & 3rd ventricle \\
\hline $4 \mathrm{~V}$ & 4th ventricle \\
\hline $4 n$ & trochlear nucleus \\
\hline 10 & dorsal motor nucleus of vagus \\
\hline 12 & hypoglossal nucleus \\
\hline ac & anterior commissure \\
\hline aca & anterior commissure, anterior part \\
\hline acp & anterior commissure, posterior part \\
\hline Acb & accumbens nucleus \\
\hline $\mathrm{ACo}$ & anterior cortical amygdaloid nucleus \\
\hline AHiPM & amygdalohippocampal area, posteromedial part \\
\hline AHP & anterior hypothalamic area, posterior part \\
\hline AI & agranular insular cortex \\
\hline alv & alveus of the hippocampus \\
\hline Amb & ambiguus nucleus \\
\hline Amyg & amygdala \\
\hline AOP & anterior olfactory nucleus, posterior part \\
\hline Apir & amygdalopiriform transition area \\
\hline APT & anterior pretectal nucleus \\
\hline $\mathrm{Aq}$ & aqueduct \\
\hline BAOT & bed nucleus of the accessory olfactory tract \\
\hline Beta. N. & beta nucleus \\
\hline BLA & basolateral amygdaloid nucleus \\
\hline bp & brachium pontis \\
\hline CAl $, 2,3$ & fields $\mathrm{CAI}-3$ of Amnon's horn \\
\hline $\mathrm{cc}$ & corpus callosum \\
\hline $\operatorname{cg}$ & cingulum \\
\hline $\mathrm{CeM}$ & central amygdaloid nucleus, medial division \\
\hline CG & central gray \\
\hline $\mathrm{Cg} 1,3$ & gyrus cinguli area 1,3 \\
\hline $\mathrm{Cl}$ & claustrum \\
\hline $\mathrm{cp}$ & cerebral peduncle \\
\hline $\mathrm{CPu}$ & caudate putamen \\
\hline $\mathrm{Cu}$ & cuneate nucleus \\
\hline Cxa & cortex-amygdala transition zone \\
\hline DA & dorsal hypothalamic area \\
\hline DC & dorsal cochlear nucleus \\
\hline Dc & dorsal cap \\
\hline DEn & dorsal endopiriform nucleus \\
\hline DfDAO & dorsal fold of the dorsal accessory olive \\
\hline DG & dentate gyrus \\
\hline $\mathrm{Dk}$ & nucleus of Darkschewitsch \\
\hline DLB & dendritic lamellar body \\
\hline DLN & dorsolateral nucleus \\
\hline DMCC & dorsal medial cell column \\
\hline DMSp5 & dorsomedial spinal trigeminal nucleus \\
\hline $\mathrm{DP}$ & dorsal peduncular cortex \\
\hline $\mathrm{DR}$ & dorsal raphe nucleus \\
\hline Ent & entorhinal cortex \\
\hline Epl & external plexiform layer of the olfactory bulb \\
\hline $\mathrm{f}^{2}$ & fornix \\
\hline fmi & forceps minor of the corpus callosum \\
\hline fr & fasciculus retroflexus \\
\hline $\operatorname{Fr} 1,2,3$ & frontal cerebral cortex area $1,2,3$ \\
\hline FStr & fundus striata \\
\hline G & gelatinosus thalamic nucleus \\
\hline $\mathrm{Gl}$ & glomerular layer of the olfactory bulb \\
\hline GP & globus pallidus \\
\hline $\mathrm{HiF}$ & hippocampal fissure \\
\hline IAM & interanteromedial thalamic nucleus \\
\hline
\end{tabular}

\section{Table 2. Continued}

\begin{tabular}{|c|c|}
\hline ic & internal capsule \\
\hline $\mathrm{ICj}$ & islands of Calleja \\
\hline icp & inferior cerebellar peducle \\
\hline Ifp & longitudinal fasciculus of the pons \\
\hline Igl & internal granular layer of the olfactory bulb \\
\hline IL & infralimbic cortex \\
\hline In & intercalated nucleus of the medulla \\
\hline IO & inferior olive \\
\hline LM & lateral mammillary nucleus \\
\hline LO & Lateral orbital cortex \\
\hline lo & lateral olfactory tract \\
\hline LPO & lateral preoptic area \\
\hline LV & lateral ventricle \\
\hline LVe & later vestibular nucleus \\
\hline MAO.a,b,c & subnuclei $a, b$, and $c$ of the caudal MAO \\
\hline Me5 & mesencephalic trigeminal nucleus \\
\hline $\mathrm{mfb}$ & medial forebrain bundle \\
\hline $\mathrm{ml}$ & medial lemniscus \\
\hline mlf & medial longitudinal fasciculus \\
\hline $\mathrm{mt}$ & mammillothalamic tract \\
\hline MPA & medial preoptic area \\
\hline MnR & median raphe nucleus \\
\hline Mve & medial vestibular nucleus \\
\hline OB & olfactory bulb \\
\hline opt & optic tract \\
\hline OPT & olivary pretectal nucleus \\
\hline OT & nucleus of the optic tract \\
\hline ox & optic chiasm \\
\hline Parl & parietal cortex, area 1 \\
\hline PDR & paradorsal raphe nucleus \\
\hline $\mathrm{Pe}$ & peri- and paraventricular hypothalamus \\
\hline PF & nucleus subparafascicularis of the thalamus \\
\hline Pir & piriform cortex \\
\hline Pirlo & piriform cortex along the lateral olfactory tract \\
\hline PMCo & posteromedial cortical amygdaloid nucleus \\
\hline Pn & pontine nuclei \\
\hline PO & principal olive \\
\hline PoDG & polymorph layer of the dentate gyrus \\
\hline $\mathrm{PrC}$ & precommissural nucleus \\
\hline py & pyramidal tract \\
\hline $\mathrm{R}$ & red nucleus \\
\hline RF & rhinal fissure \\
\hline RI & rostral interstitial nucleus of the mlf \\
\hline $\operatorname{ReF}$ & reticular formation \\
\hline rMAO & rostral medial accessory olive \\
\hline Ro & nucleus of Roller \\
\hline RPO & rostral periolivary region \\
\hline s5 & sensory root of the trigeminal nerve \\
\hline$S$ & subiculum \\
\hline $\operatorname{scp}$ & superior cerebellar peduncle \\
\hline SG & stratum granulosum \\
\hline SLM & stratum lacunosum moleculare \\
\hline SM & stratum moleculare \\
\hline SNB & spinal nucleus of the bulbocavernosus \\
\hline SNR & substantia nigra, reticular part \\
\hline SO & supraoptic nucleus \\
\hline sol & solitary tract \\
\hline Sol & nucleus of the solitary tract \\
\hline sox & supraoptic decussation \\
\hline sp5 & spinal trigeminal tract \\
\hline
\end{tabular}


Table 2. Continued

\begin{tabular}{ll}
\hline Sp5I & spinal trigeminal nucleus, interpolar part \\
SP & stratum pyramidale \\
SR & stratum radiatum \\
SuG & superficial gray layer of the superior colliculus \\
TT & tenia tecta \\
VC & ventral cochlear nucleus \\
VEn & ventral endopiriform nucleus \\
VfDAO & ventral fold of the dorsal accessory olive \\
VL & ventrolateral thalamic nucleus \\
VLL & ventral nucleus of the lateral lemniscus \\
VM & ventromedial thalamic nucleus \\
VMH & ventromedial hypothalamic nucleus \\
VLO & ventrolateral outgrowth \\
Zo & zonal layer of the superior colliculus \\
\hline
\end{tabular}

formation of the gap junction hemichannel or connexon. Musil and Goodenough (1993) demonstrated in cultured cells that Cx43 subunits oligomerize into these hemichannels in the trans Golgi network (see also Evans, 1994). This process appears unique among integral plasma membrane proteins and may require a special Golgi-like organelle when it occurs in the distal dendrites remote from the cell body, especially since gap junctions have a fast turnover of only a few hours (Herizberg el al., 1989; Laird et al., 1991).

In summary, (1) The DLBs exist in all brain areas where dendrodendritic gap junctions are prominent; (2) the DLBs in the IO appear in the same developmental period as the dendrodendritic gap junctions; (3) the DLBs in the IO are most numerous in the subnucleus where electrotonic coupling is most prominent; and (4) the DLBs are exclusively located in dendritic appendages. Based on these observations, we propose that the DLBs are associated with regions or neurons expressing dendrodendritic gap junctions and that they may be involved in their synthesis.

\section{References}

Andrew RD, Mac Vicar BA, Dudek FE, Hatton GI (1981) Dye transfer through gap junctions between neuroendocrine cells of rat hypothalamus. Science 211:1187-1189.

Andrew RD, Taylor CP, Snow RW, Dudek FE (1982) Coupling in rat hippocampal slices: dye transfer between CA1 pyramidal cells. Brain Res Bull 8:211-222.

Angaut P, Sotelo C (1989) Synaptology of the cerebello-olivary pathway. Double labeling with anterograde axonal tracing and GABA immunocytochemistry in the rat. Brain Res 479:361 365 .

Baker R, Llinás R (1971) Electrotonic coupling between neurons in the rat mesencephalic nucleus. J Physiol (Lond) 212:45-63.

Benardo LS, Foster RE (1986) Oscillatory behaviour in inferior olive neurons: mechanism, modulation, cell aggregates. Brain Res Bull 17: 773-784.

Bennett MVL, Goodenough DA (19/8) Gap junctions, electrotonic coupling and intracellular communication. Neurosci Res Prog Bull 16:373-486.

Beyer EC, Paul DL, Goodenough DA (1987) A protein from rat heart homologous to a gap junction protein from liver. J Cell Biol 105: 2621-2629.

Blackstad TW (1967) Cortical gray matter. A correlation of light and electron microscopic data. In: The neuron (Hyden $\mathrm{H}$, ed), pp 49-118. Amsterdam: Elsevier.

Bourrat F, Sotelo C (1983) Postnatal development of the inferior olivary complex in the rat. I. An electron microscopic study of the medial accessory olive. Dev Brain Res 8:291-310.

Church J, Baimbridge KG (1991) Exposure to high-pH medium in- creases the incidence and extent of dye coupling between rat hippocampal CA1 pyramidal neurons in vitro. J Neurosci 11:3289-3295. Cobbett P, Smithson KG, Hatton GI (1985) Dye-coupled magnocellular peptidergic neurons of the rat paraventricular nucleus show homotypic immunoreactivity. Neuroscience 16:885-895.

Connors BW, Benardo LS, Prince DA (1983) Coupling between neurons of the developing rat neocortex. J Neurosci 3:773-782.

Dermietzel R, Traub O, Hwang TK, Beyer E, Bennett MVL, Spray DC, Willecke K (1989) Differential expression of three gap junction proteins in developing and mature brain tissues. Proc Natl Acad Sci USA $86: 10148-10152$.

Dermietzel R, Hertzberg EL, Kesslar JA, Spray D (1991) Gap junctions between cultured astrocytes: immunocytochenical, molecular, electrophysiological analysis. J Neurosci 11:1421-1432.

Desclin JC (1974) Histological evidence supporting the inferior olive as the major source of the cerebellar climbing fibers in the rat. Brain Res 77:365-384

De Zeeuw CI, Holstege JC, Ruigrok TJH, Voogd J (1989) An ultrastructural study of the GABAergic, the cerebellar and the mesodiencephalic innervation of the cat medial accessory olive: anterograde tracing combined with immunocytochemistry. J Comp Neurol 284: $12-35$.

De Zeeuw CI, Ruigrok TJH, Holstege JC, Jansen HG, Voogd J (1990a) Intracellular labeling of neurons in the medial accessory olive of the cat. II. Ultrastructure of dendritic spines and their GABAergic innervation. J Comp Neurol 300:478-494.

De Zeeuw CI, Holstege JC, Ruigrok TJH, Voogd J (1990b) Mesodiencephalic and cerebellar terminals end upon the same dendritic spines within the glomeruli of the cat and rat inferior olive: an ultrastructural study using a combination of $(3 \mathrm{H})$ leucine and WGA-HRP anterograde tracing. Neuroscience 34:645-655.

De Zeeuw CI, Wentzel P, Mugnaini E (1993) Fine structure of the dorsal cap of the inferior olive and its GABAergic and non-GABAergic input from the nucleus prepositus hypoglossi in rat and rabbit. J Comp Neurol 327:63 82.

Eccles JC, Llinás R, Sasaki K (1966) The excitatory synaptic action of climbing fibers on the Purkinje cells of the cerebellum. J Physiol (Lond) 182:268-296.

Evans WH (1994) Hiroshima welcomes gap junction communicants. Trends Cell Biol 4:26-29.

Fishman GI, Spray DC, Leinwand LA (1990) Molecular characterization and functional expression of the human cardiac gap junction channel. J Cell Biol 111:589-598.

Fredette BJ, Adams JC, Mugnaini E (1992) GABAergic neurons in the mammalian inferior olive and ventral medulla detected by glutamate decarboxylase immunocytochemistry. J Comp Neurol 321:501-514.

Glantz SA (1981) Primer of biostatistics, pp 63-90. New York: McGraw-Hill.

Gray EG (1959) Axo-somatic and axo-dendritic synapses of the cerebral cortex: an electron microscope study. J Anat (Lond) 93:420-433.

Gray EG, Guillery RW (1963) A note on the dendritic spine apparatus. J Anat (Lond) 97:389-392.

Gwyn DG, Nicholson GP, Flumerfelt BA (1977) The inferior olivary nucleus of the rat: a light and electron microscopic study. J Comp Neurol 174:489-520.

Hamlyn LH (1962) The fine structure of the mossy fiber endings in the hippocampus of the rabbit. I Anat (I ond) 96:112-120.

Hertzberg EL, Corpina R, Roy C, Dougherty MJ, Kessler JA (1989) Analysis of the $43 \mathrm{kDa}$ heart gap junction protein in primary cultures of rat leptomeningeal cells. J Cell Biol 109:47a.

Hinrichsen CFL, Larramendi LMH (1968) Synapses and cluster formation in the mouse mesencephalic fifth nucleus. Brain Res 7:296299.

Hinrichsen CFL, Larramendi LMH (1970) The trigeminal mesencephalic nucleus. II. Electron microscopy. Am J Anat 127:303-320.

Hoh JH, Sosinsky GE, Revel JP, Hansma PK (1993) Structure of the extracellular surface of the gap junction by atomic force microscopy. J Biophysiol 65:149-163.

Hossain MZ, Murphy LJ, Hertzberg EL, Nagy JI (1994) Phosphorylated forms of connexin 43 predominate in rat brain: demonstration by rapid inactivation of brain metabolism. $J$ Neurochem, in press.

John SA, Revel JP (1991) Connexon integrity is maintained by noncovalent bonds: intramolecular disulfide bonds link the extracellular domains in rat $\mathrm{Cx}-43$. Biochem Biophys Res Commun 178:13121318 . 
Karnovsky MJ (1971) Use of ferrocyanide-reduced osmium tetroxide in electron microscopy. Am Soc Cell Biol Abstr 146.

King JS (1980) The synaptic organization of the inferior olivary nucleus. In: The inferior olivary nucleus (Courville $\mathbf{J}$, de Montigny $\mathbf{C}$, Lamarre Y, eds), pp 1-35. New York: Raven.

Kosaka T, Hama K (1985) Gap junctions between non-pyramidal cell dendrites in the rat hippocampus (CA1 and CA3 regions): a combined Golgi-electron microscopy study. J Comp Neurol 231:150-161.

Kruger L, Maxwell DS (1969) Cytoplasmic laminar bodies in the striate cortex. J Ultrastruct Res 26:387-390.

Kumar NM, Gilula NB (1992) Molecular biology and genetics of gap junction channels. Cell Biol 3:3-16.

Laird DW, Puranam KL, Revel JP (1991) Turnover and phosphorylation dynamics of connexin 43 gap junction protein in cultured cardiac myocytes. Biochem J 273:67-72.

Landis DMD, Reese TS, Raviola E (1974) Differences in membrane structure between excitatory and inhibitory components of the reciprocal synapse in the olfactory bulb. J Comp Neurol 155:67-92.

Lang EJ, Chou M, Sugihara I, Llinás R (1989) Intraolivary injection of picrotoxin causes reorganization of complex spike activity. Soc Neurosci Abstr 15:77.5.

Lang EJ, Sugihara I, Llinás R (1990) Lesions of the cerebellar nuclei, but not of mesencephalic structures alters the spatial pattern of complex spike synchronicity as demonstrated by multiple electrode recordings. Soc Neurosci Abstr 16:370.3.

Llinás R (1974) 18th Bowditch lecture: motor aspects of cerebellar control. Physiologist 17:19-46.

Llinás R, Yarom Y (1981) Electrophysiology of mammalian inferior olivary neurons in vitro. Different types of voltage-dependent ionic conductances. J Physiol (Lond) 315:549-567.

Llinás R, Sasaki K (1989) The functional organization of the olivocerebellar system as examined by multiple Purkinje cell recordings. Eur J Neurosci 1:587-602.

Llinás R, Baker R, Sotelo C (1974) Electrotonic coupling between neurons in cat inferior olive. J Neurophysiol 37:560-571.

Loewenstein WR (1981) Junctional intercellular communication: the cell-to-cell membrane channel. Physiol Rev 61:829-913.

MacVicar BA, Dudek FE (1980) Dye-coupling between CA3 pyramidal cells in slices of rat hippocampus. Brain Res 196:494-497.

MacVicar BA, Dudek FE (1981) Electrotonic coupling between pyramidal cells: a direct demonstration in rat hippocampal slices. Science 213:782-785

MacVicar BA, Dudek FE (1982) Electrotonic coupling between granule cells of rat dentate gyrus: physiological and anatomical evidence. J Neurophysiol 47:579-592.

MacVicar BA, Ropert N, Krnjevic K (1982) Dye-coupling between pyramidal cells of rat hippocampus in vivo. Brain Res 238:239-244.

Massa PT, Mugnaini E (1982) Cell junctions and intramembrane particles of astrocytes: a freeze-fracture study. Neuroscience 7:523-538.

Matsumoto A, Arnold AP, Zampighi GA, Micevych PE (1988) Androgenic regulation of gap junctions between motoneurons in rat spinal cord. J Neurosci 8:4177-4183.

Matsumoto A, Arnold AP, Micevych PE (1989) Gap junctions between lateral spinal motoneurons in the rat. Brain Res 496:362-366.

Matsumoto A, Arai Y, Urano A, Hyodo S (1991) Cellular localization of gap junction mRNA in the neonatal brain. Neurosci Lett 124:225228.

Micevych PE, Abelson L (1991) Distribution of mRNAs coding for liver and heart gap junction proteins in the rat central nervous system. J Comp Neurol 305:96-118.

Morales R, Duncan D (1966) Multilaminated bodies and other unusual configurations of endoplasmic reticulum in the cerebellum of the cat. An electron microscopic study. J Ultrastruct Res 15:480-489.

Morales R, Duncan D, Rehmet R (1964) A distinctive laminated cytoplasmic body in the lateral geniculate body neurons of the cat. $\mathrm{J}$ Uitrastruct Res 10:116-123.

Mugnaini E (1972) The histology and cytology of the cerebellar cortex. In: The comparative anatomy and histology of the cerebellum. The human cerebellum, cerebellar connections, and cerebellar cortex (Larsell O, Jansen J, eds), pp 201-264. Minneapolis: University of Minnesota.

Mugnaini E (1986) Cell junctions of astrocytes, ependyma, and related cells in the mammalian central nervous system, with emphasis on the hypothesis of a generalized functional syncytium of supporting cells. In: Astrocytes, development, morphology, and regional specialization of astrocytes, Vol 1 (Fedoroff S, Vernadakis A, eds), pp 329-371. New York: Academic.

Musil LS, Goodenough DA (1993) Multisubunit assembly of an integral plasma membrane channel protein, gap junction connexin 43 , occurs after exit from the ER. Cell 74:1065-1077.

Musil LS, Cunningham BA, Edelman GM, Goodenough DA (1990) Differential phosphorylation of the gap junction protein connexin43 in junctional communication-competent and -deficient cell lines. $J$ Cell Biol 111:2077-2088.

Nagy JI, Yamamoto T, Shiosaka S, Dewar KM, Whittaker ME, Hertzberg EL (1988) Immunohistochemical localization of gap junction protein in rat CNS: a preliminary account. In: Modern cell biology, Vol 7 (Hertzberg EL, Johnson RG, eds), pp 375-389. New York: Liss.

Nagy JI, Yamamoto T, Carr PA, Hertzberg EL (1989) Immunohistochemical localization of the $27 \mathrm{kD}$ and $43 \mathrm{kD}$ gap junction proteins in the central nervous system. Soc Neurosci Abstr 15:276.2.

Naus CCG, Belliveau DJ, Bechberger JF (1990) Regional differences in connexin32 and connexin43 messenger RNAs in rat brain. Neurosci Lett 111:297-302.

Nelson B, Mugnaini E (1988) The rat inferior olive as seen with immunostaining for glutamic decarboxylase. Anat Embryol 179:109 127.

Paxinos C, Watson C. (1986) The rat brain in stereotaxic coordinates, 2d ed, pp CC1-CC75. Sydney: Academic.

Peters A (1980) Morphological correlates of epilepsy: cells in the cerebral cortex. In: Anticpileptic drugs: mechanisms of action (Glaser GH, Penry JK, Woodbury DM, eds), pp 21-48. New York: Raven.

Peters A, Palay SL (1966) The morphology of lamina A and Al of the dorsal nucleus of the lateral geniculate body of the cat. $J$ Anat 100:451-486.

Peters A, Palay SL, Webster HF (1970) The fine structure of the nervous system, pp 34-36, 142, 156-161, 168. New York: Harper and Row.

Ramón y Cajal S (1909-1911) Histologie du système nerveux de l'homme et des vertébrés, Vols I and II. Paris: Maloine. Reprint. Madrid: Consejo Superior de Investigaciones Cientificas, 1952.

Reyher CK, Lubke J, Larsen WJ, Hendrix GM, Shipley MT, Baumgarten HG (1991) Olfactory bulb granule cell aggregates: morphological evidence for interperikaryal electrotonic coupling via gap junctions. J Neurosci 11:1485-1495.

Robertson JD (1963) The occurrence of a subunit pattern in the unit membranes of club endings in Mauthner cell synapses in goldfish brains. J Cell Biol 19:201-221.

Ruigrok TJH, De Zeeuw CI, van den Burg J, Voogd J (1990) Intracellular labeling of neurons in the medial accessory olive of the cat. I. Physiology and light microscopy. J Comp Neurol 300:458-477.

Rutherford JG, Gwyn DG (1977) Gap junctions in the inferior olivary nucleus of the squirrel monkey, Saimiri sciureus. Brain Res 128:374378.

Rutherford JG, Gwyn DG (1980) A light and electron microscopic study of the inferior olivary nucleus of the squirrel monkey, Saimiri sciureus. J Comp Neurol 189:127-155.

Sasaki K, Bower JM, Llinás R (1989) Multiple Purkinje cell recording in rodent cerebellar cortex. Eur J Neurosci 1:572-586.

Schmalbruch H, Jahnsen H (1981) Gap junctions on CA3 pyramidal cells of guinea pig hippocampus shown by freeze-fracture. Brain Res 217:175-178.

Shepherd GM (1990) The synaptic organization of the brain, pp 145146. New York: Oxford UP.

Shiosaka S, Yamamoto T, Hertzberg EL, Nagy JI (1989) Gap junction protein in rat hippocampus: correlative light and electron microscope immunohistochemical localization. J Comp Neurol 281:282-297.

Sloper JJ (1972) Gap junctions between dendrites in the primate neocortex. Brain Res 44:641-646.

Sunith DE, Moskovitz N (1979) Ultrastructure of layer IV of the primary auditory cortex of the squirrel monkey. Neuroscience 4:349360 .

Somogyi P, Hodgson AJ, Smith AD, Nunzi MG, Gorio A, Wu J (1984) Different populations of GABAergic neurons in the visual cortex and hippocampus of cat contain somatostatin- or cholecystokinin-immunoreactive material. J Neurosci 4:2590-2603.

Sotelo C, Korn H (1978) Morphological correlates of electrical and other interactions through low-resistance pathways between neurons of the vertebrate central nervous system. Int Rev Cytol 55:67-107. 
Sotelo C, Llinás R (1972) Specialized membrane junctions between ncurons in the vertebrate cerebellar cortex. J Cell Biol 53:271-289.

Sotelo C, Palay SL (1970) The fine structure of the lateral vestibular nucleus in the rat. II. Synaptic organization. 18:93-115.

Sotelo C, Triller A (1981) Morphological correlates of electrical, chemical and dual modes of transmission. In: Chemical neurotransmission 75 years (Stjarne L, Hedquist P, Lagercrantz H, Wennmaln A, eds), pp 13-28. London: Academic.

Sotelo C, Llinás R, Baker R (1974) Structural study of inferior olivary nucleus of the cat: morphological correlates of electrotonic coupling. J Neurophysiol 37:541-559.

Sotelo C, Gentschev T, Zamora AJ (1976) Gap junctions in ventral cochlear nucleus of the rat. A possible new example of electrotonic junctions in the mammalian C.N.S. Neuroscience 1:5-7.

Szentágothai J, Rajkovits K (1959) Ueber den Ursprung der Kletterfasern des Kleinhirns. Z Arlat Entwicklungsgesch 121:130-141.

Valverde $F$ (1965) Studies on the piriform lobe, pp 60-69. Cambridge, MA: Harvard UP.

Watson ML (1955) The nuclear envelope: its structure and relation to cytoplasmic membranes. J Biophys Biochem Cytol 1:257-270.

Westrum LE, Blackstad TW (1962) An electron microscopic study of the stratum radiatum of the rat hippocampus (regio superior, CA 1) with particular emphasis on synaptology. J Comp Neurol 119:281309.

Wouterlood FG, Mugnaini E, Olsen KK, Dahl AL (1984) Stellate neurons in rat dorsal cochlear nucleus studied with combined Golgi impregnations and electron microscopy: synaptic connections and mutual coupling by gap junctions. J Neurocytol 13:639-664.

Wouterlood FG, Mugnaini E, Nederlof J (1985) Projection of olfactory bulb efferents to layer I GABAergic neurons in the entorhinal area Combination of anterograde degeneration and immunuelectron microscopy. Brain Res 343:283-296.

Wylie DR, De Zeeuw CI, Wang D, Simpson JI (1993) Temporal relations of the activity of Purkinje cell pairs in the rabbit nodulus. Soc Neurosci Abstr 529.8.

Yamamoto T, Shiosaka S, Whittaker ME, Hertzberg EL, Nagy JI (1989a) Gap junction protein in rat hippocampus: light microscope immunohistochemical localization. J Comp Neurol 281:229-281.

Yamamoto T, Hertzberg EL, Nagy JI (1989b) Antibodies against rat liver connexin 32 recognize subsurface cisterns in motoneurons: immunohistochemical evidence for similarities between gap junctional and subcisternal proteins. Soc Neurosci Ahstr 680.

Yamamoto T, Ochalski A, Hertzberg EL, Nagy JI (1990a) LM and EM immunolocalization of the gap junctional protein connexin 43 in rat brain. Brain Res 508:313-319.

Yamamoto T, Hertzberg EL, Nagy JI (1990b) Epitopes of gap junctional proteins localized to neuronal subsurface cisterns. Brain Res 527:135-139.

Yamamoto T, Ochalski A, Hertzberg EL, Nagy JI (1990c) On the organization of astrocytic gap junctions in rat brain as suggested by LM and EM immunohistuchemistry of connexin43 expression. J Comp Neurol 302:853-883.

Yamamoto T, Hertzberg EL, Nagy JI (1991) Subsurface cisterns in $\alpha$-motoneurons of the rat and cat: immunohistochemical detection with antibodies against connexin32. Synapse 8:119-137.

Yancey SB (I), John SA (II), Lal R (III), Austin BJ, Revel JP (1989) The $43 \mathrm{kD}$ polypeptide of heart gap junctions: immunolocalization (I) topology (II), and functional domains (III). J Cell Biol 108:22412254. 